\title{
EVALUATION OF REFLECTANCE FOR BUILDING MATERIALS CLASSIFICATION WITH TERRESTRIAL LASER SCANNER RADIATION
}

\author{
Domenica Costantino ${ }^{a, *}$, Massimiliano PePE $^{a}$, \\ Maria Giuseppa Angelinit ${ }^{b}$ \\ a Polytechnic University of Bari, Department of Civil, Environmental, Land, Building Engineering and \\ Chemistry (DICATECh), Via E. Orabona 4, 70126 Bari, Italy \\ ${ }^{b}$ Polytechnic University of Bari, Architectural $\& 5$ Engineering Survey of Environmental and Infrastructure \\ (AESEI Srl Spin-off), Via S. Eligio 1/l, 74100 Martina Franca, Italy \\ * corresponding author: domenica.costantino@poliba.it
}

\begin{abstract}
The main purpose of this work is the evaluation of the potential of Terrestrial Laser Scanning (TLS) technology to perform a reflectance analysis of scanned objects. A laser beam, having a coherent beam in the field of visible light (wavelength between $532 \mathrm{~nm}$ and $680 \mathrm{~nm}$ ), can lead to optical diffraction phenomena that allow a correlation between the degree of crystallinity of solids (in particular dispersed crystalline materials) and its reflectivity. Different materials with known crystallinity values have been examined and the diffraction value has been analysed for two types of lasers, one pulsed and the other phase measurement, with two different acquisition conditions (nadiral and oblique position). The results demonstrated the correlation by verifying that the incident laser light beam is more refracted by materials with a higher degree of crystallinity than less crystalline or amorphous materials.
\end{abstract}

KEYWORDS: TLS, reflectance, materials, classification, crystallinity.

\section{INTRODUCTION}

The Terrestrial Laser Scanning (TLS) send an energy flow on object's surface and its geometry is measured on the basis of the definition of an optical quantity of a portion of reflective energy. The laser ray lights an artificial surface in order to acquire a threedimensional (xyz) point cloud with a high-density and high-accuracy [1, 2]. The output of a scan is typically a point cloud of $\mathrm{n}$ observations consisting of $3 \mathrm{D}$ positions $\left(x_{i}, y_{i}, z_{i}\right) i=1 \ldots n$ of each point in a Cartesian coordinate system with the origin in the laser scanner centre, as well as an uncalibrated intensity value of the reflected light. The Cartesian coordinates are obtained by the transformation of the spherical coordinates to a Cartesian coordinate system [3, 4]. The scanner mechanism operates in a spherical coordinate system, with regular horizontal and vertical angle increments. The scanner detects the returned signal of reflection on a surface and records the two directional angles (horizontal angle, or longitude, $\theta_{i}$, and vertical angle, or latitude, $\varphi_{i}$ ) and measures the range $\rho_{i}$ to the object surface.

The TLS uses these principles; time-of-flight (TOF) and phase-shift (PS). In the TOF, a short laser pulse is emitted towards the target and reflected from the surface; the scanner detector measures the difference of the sending and arrival time [5 5 ]. In the PS measurement method, the distance is determined by the phase difference between the sent and received waveforms.

The quality of the acquired data is influenced by the acquisition method, the specifications of the laser scanning instrument and the reflectance characteristics of the materials 8 . Therefore, the TLS provides $3 \mathrm{D}$ geometrical information about the measured object and information about the power of the backscatter laser beam by the scanned surface [9].

The main terrestrial laser instruments record the intensity of the return wave as a Digital Number (DN) between a minimum threshold value and the maximum recorded in the reflective targets. This DN, which represents the back scattered signal, is mainly a function of some important physical quantities, such as the direction of the light source with respect to the observed object, i.e., the direction of the incident energy, the distance from the object, the wavelength used, the surface reflectance, the thermo-hygrometric conditions of the electromagnetic wave propagation medium and the proximity of the affected object to other highly reflective bodies [10]. Return wave intensity measurements were mainly used to support the visual analysis of a point cloud and also for different applications, such as for orientation [11, recording [12], manual inspection of trees [13, rock face investigation [14 or classification based on the surface material properties [15, 16].

The error sources of range measurements such as detection errors on backscattered pulses are the function of signal level, background illumination and effects of different heights inside a laser spot [17]. The errors of range measurements are closely related to the object's reflectivity and to the measure distance of the object. 
Extreme reflection values imply a signal saturation within the laser scanner internal sensor, and therefore, they cause a deletion of data (Boehler, 2003) [18, occurrence for dark surfaces. Kersten et al. (2008) [19] created a test field for laser scanners of different kinds (brands and models); other scientists investigated the influence of the distance of the measures as well as laser ray incidence angle. Kukko et al. (2008) [20] carried out a comprehensive study on the effect of laser ray different incidence angles on the laser scanners intensity measurements.

In this paper, we conducted a qualitative analysis of the materials used in construction, scanned by a TLS to obtain information on their composition.

\subsection{TheOreticAl BACKGROUND}

TLS technology can accurately measure the distance to object surfaces by emitting laser light in known angular directions and measuring reflected signals in the direction of the emission. The detection of the reflected signal requires a good Signal-to-Noise Ratio (SNR). To quantify the amount of the received signal compared to the emitted signal, the energy balance between the laser light transmitter and the detection unit is described. The energy balance takes into account the signal attenuation due to the propagation as well as other possible signal deterioration and allows the SNR characterization. In the case of the laser scanner, a bidirectional energy balance has been designed (Figure 1), i.e., a laser beam is emitted by the transmitter towards a surface, which receives an amount of energy contained within a footprint and, depending on the reflectance properties of the surface, a certain amount of energy is reflected.

On the way back, the energy is reflected and dispersed in directions defined by the reflectivity properties of the surface. Located in the same position as the laser transmitter, the detection unit measures the backscatter reflected signals within a given field of view. The signal received by a LiDAR detector is mainly influenced by four essential factors: instrumental and atmospheric effects, target dispersion characteristics and measurement geometry. The basic equation to describe the force of backscatter from an object surface summarizes all the relevant parameters to describe these effects and the power of the backscattered signal in a laser scanner detector. All influences can be summarized in the laser equation [21, which correlates the emitted optical power $P_{E}$ to the transmitted optical power $P_{R}$ :

$$
P_{R}=\frac{\pi P_{E} \rho \cos (\alpha)}{4 r^{2}} \eta_{\text {Atm }} \eta_{\text {Sys }}
$$

\author{
where \\ $P_{R} \quad$ transmitted optical power; \\ $P_{E} \quad$ emitted optical power; \\ $\alpha \quad$ angle of incidence; \\ $\rho \quad$ material reflectance coefficient; \\ $\eta_{\text {Atm }}$ atmospheric transmission factor; \\ $\eta_{\text {Sys }} \quad$ system-caused transmission factor; \\ $r$ range.
}

The received signal is usually converted into an amplified electrical signal and then digitized (DN). Both the detector and the data processing software can introduce some normalizations at any step of the acquisition, export or processing of the data, causing a loss of intensity information. For example, Leica Cyclone software automatically applies an arbitrary scaling of intensity data to improve, for example, the visual appearance [22, 23]. The ZF-Laser software, instead, does not scale the signal so the intensity scale is linear [24]. It is, therefore, important to recognize the possible effects on the data and this can be done by considering a reference scale with known reflectance values such as reference targets. The angle of incidence has an effect on the data quality. The laser footprint increases significantly as the angle of incidence increases [25]. The optimal condition is a normal angle of incidence, but this is not always possible, especially in TLS mobile applications.

The main objective of this experiment is to obtain not only the information on the topography and morphology of an object, but also the characteristics of the materials. The geometric information of the scanned objects refers to the selected sample data, which is not the subject of the investigation. The survey focuses on the ability to discriminate from the data acquired with the TLS in relation to the type of material.

In the first part of the paper, the state of the art and basic concepts for the determination of the physical characteristics of materials are described. Subsequently, a method for analysing the reflectance of different samples of building materials measured through the TLS instruments is illustrated.

After introducing the types and features of the TLS used for the experimentation, the paper shows the relation between sample building material and reflectance varying the type of the TLS and acquisition scheme (Left or Nadir acquisition). Conclusions are summarized at the end of the paper.

\section{MATERIALS AND METHODS}

\subsection{INSTRUMENTS USED FOR EXPERIMENTATION}

For each scanning system, the reflected optical power is converted by means of an ADC system (analogicto-digital converter) into digital information so that it can be processed by any digital processor. The ADC conversion starts when the converter is activated. Depending on the speed of the ADC, the actual conversion process may take several microseconds. The parameters that come into play in this 


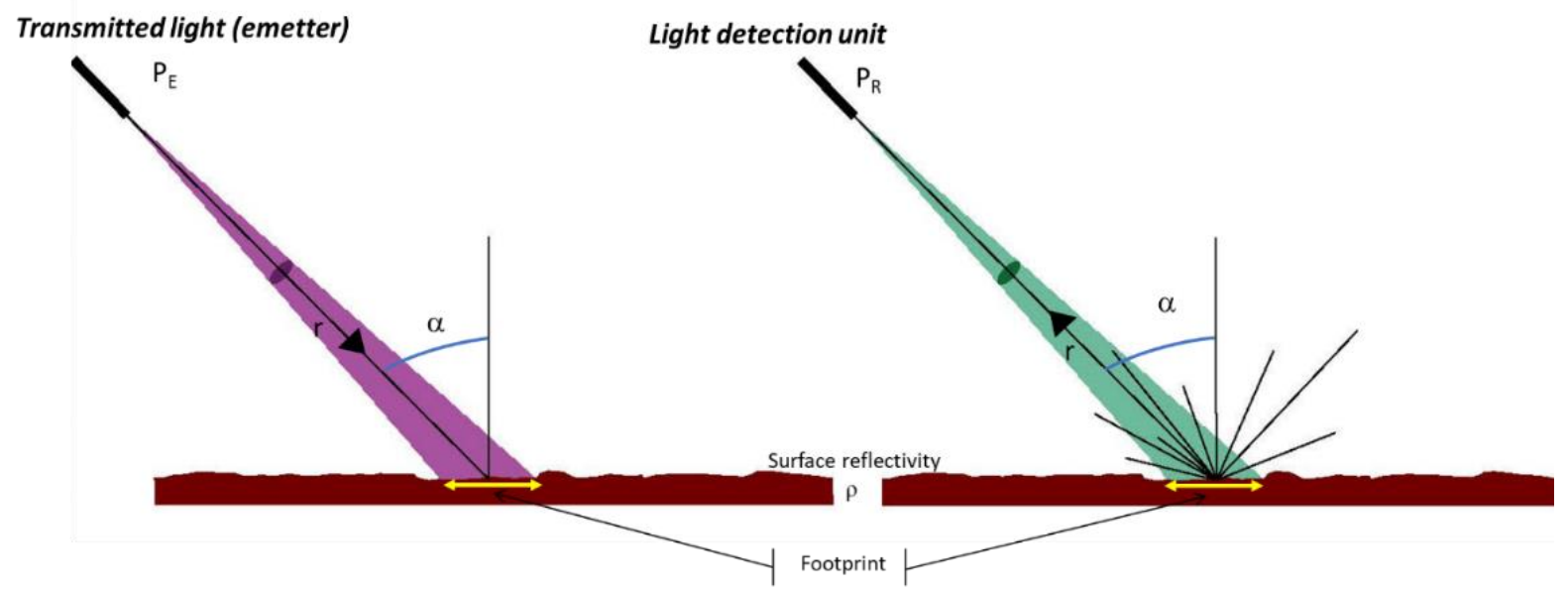

FigURE 1. Backscattered reflectance function of surface reflectivity and the angle of incidence.

process are resolution (number of bits produced) and noise level (how many of these bits are stored). In paragraph 1.1 it has been underlined that both the detector and the data processing software can introduce some normalizations at any stage: acquisition, export or processing of the data causing a loss of intensity information. Even if todaythough the ADCs on the market allow to increase the speed performance of scanning systems, it has been chosen to operate with a suitable TLS instrumentation. In fact, it was chosen decided to choose instruments of which the Target accuracy was known and was the lowest among those on the market. In particular, in order to make the most of the incoming information from the TLS and verify it on a single software (Cyclone), it was decided to perform the experimentation with the TLS HDS3000 (target accuracy $1.5 \mathrm{~mm}$ ) and HDS 6100 (target accuracy $2 \mathrm{~mm}$ ). This made it possible to measure the reflectance range for both instruments. Specifically, Leica TLS HDS3000 (characterized by laser light visible in the region of the green, with a wavelength equal to $532 \mathrm{~nm}$, and a continuous power output less than $5 \mathrm{~mW}$ ) [26, 27 and a Leica TLS HDS6100 (characterized by laser light visible in the region of the red with a wavelength equal to $680 \mathrm{~nm}$, and a continuous power output less than $5 \mathrm{~mW}$ ) were used. The main features of the terrestrial laser scanners used in the experimentations are summarized in Appendix A.1.

\subsection{EXPERIMENTAL SETUP}

In order to achieve our aims, some repeatable experiments were carried out by the use of various Terrestrial Laser Scanners. In particular, pulse TLS and phase shift TLS were used for the experimentation. As for the targets, they have an appropriate size such as to be considered extended targets.

In addition, the atmospheric transmission factor was neglected because the range maximum was of $3 \mathrm{~m}$ in a standard clear atmosphere and, under these conditions, the mentioned factor does not fall below $99 \%$.
Laboratory tests on material samples of various kinds and origins were carried out in order to verify the possible reflectance variation of the reflected laser beam coming from terrestrial laser instrumentation.

It is known from the literature that laser radiation in the visible frequency may cause optical interference as a response to the interaction with solid crystalline materials and consequently, luminous diffraction phenomena, that are characteristics of the crystalline structure of the material itself, may establish [28]. Therefore, in the carried out experiments, some samples of materials characterized by a various degree of crystallinity were selected, as shown in Table 1. The values of the degree of crystallinity, reported in the Table 1] were provided by manufacturer or taken from specific literature 29 .

The samples were fitted on a plastic frame made in such a way that the target surfaces lie in one plane. The plastic frames contained some markers easily identifiable in the analysis of laser scanning intensity; in this way, it is possible to establish a local coordinate system. All scans were carried out with the highest possible density, i.e., with a resolution scan of $1 \mathrm{~mm}$. This setting involves long acquiring times. Therefore, in order to reduce the time, a window that select only the survey area was set manually in the scanner control software.

Figure 2 shows the survey scheme with the TLS considering the samples in two different positions of acquisition. The data were acquired from a position almost nadir compared to the sample (referred to below as Nadir) and from another position where the recovered laser beam forms an angle of $23^{\circ}$ to the nadir (referred to below as Left). The distance between the laser to the plastic frame, in Nadir position, was $2.78 \mathrm{~m}$, while the distance of the Left and Nadir positions was $1.18 \mathrm{~m}$.

\subsection{The ANALYSIS OF EXPERIMENTAL DATA}

The acquired parameters during the scans were the Reflectance (R), the Cartesian coordinates ( $\mathrm{mm}$ ) and 


\begin{tabular}{lc}
\hline Sample & Crystallinity (\%) \\
\hline Rough cement plaster & $25-35$ \\
Smooth cement plaster & $25-35$ \\
White lime plaster & $25-35$ \\
Colored lime plaster & $25-35$ \\
Glass & 15 \\
Frosted glass & 28 \\
Brass & $80-85$ \\
Steel & $70-75$ \\
PMMA (Plexiglass) & none \\
TFE (Tetrafluoroetene) & $2-2.15$ \\
HDPE (High-density polyethylene) & 92 \\
\hline
\end{tabular}

TABLE 1. Crystallinity of sample materials.

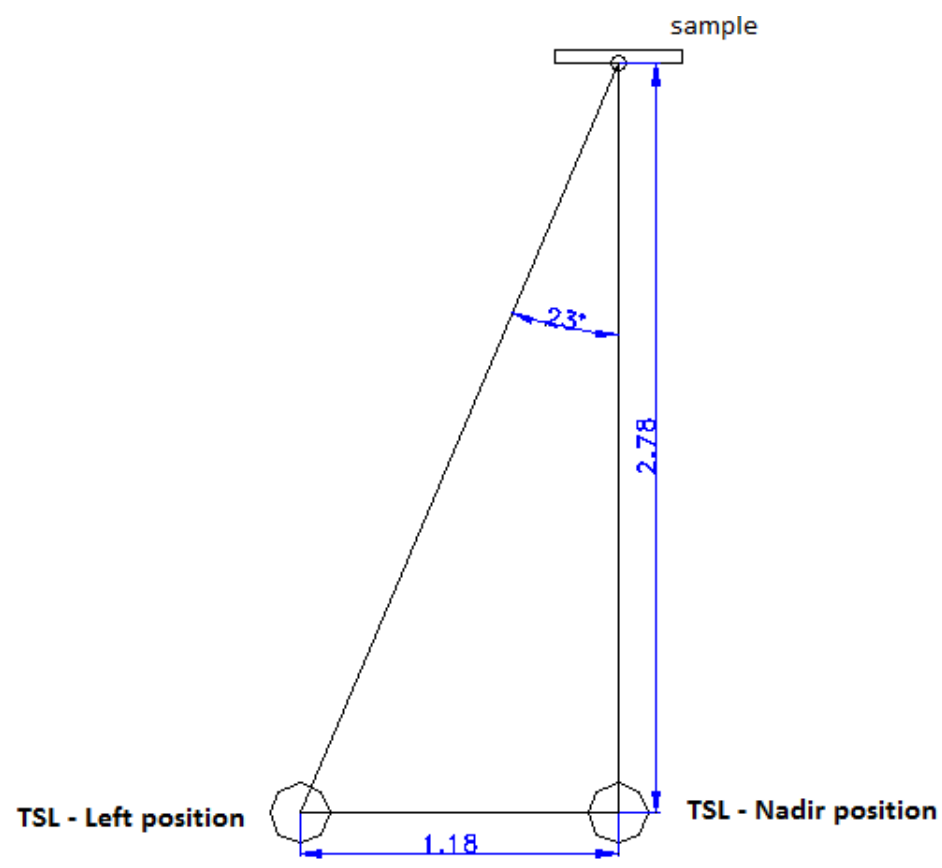

Figure 2. Acquisition scheme in Nadir and Left position.

the RGB (Red-Green-Blue colour) information. However, the RGB information was excluded from the analysis after the start of the trials. The values of these parameters were extrapolated from the collected data in relation to the lines corresponding to the position at $90^{\circ}$ zenith and azimuthal amplitude of $5^{\circ}$ in the Nadir (N) and Left (L) positions and were exported in ASCII files (Figure 3).

Such an experiment is, therefore, one set of observations, containing multiple scans, to be analysed.

The following data were calculated from the reported measurements to each target, at the different ranges, incidence angles, etc.,

$I \quad$ mean of the reflectance values;

$\sigma_{I} \quad$ standard deviation of the reflectance values;

$D$ mean of the distances.

The post-processing of data was carried out in Microsoft Excel. Table 2 shows the values of $I, \sigma_{I}$ and $D$ for Nadir acquisition evaluated on several materials.
The previous table does not show some values of $I$ related to the scanning by TLS HDS6100, such as steel, brass and PMMA, because the TLS did not record the scanned data; this could be caused by a signal saturation.

Following the procedure as described above, a Left position scan was performed. The values obtained on the different materials can be summarized as follows (Table 3).

The analysed datasets were reported in a diagram where the abscissae represent the acquisition amplitude at zenith $90^{\circ}$, limited to the interval $\pm 1^{\circ}$, while the ordinates represent the reflectance values measured by the TLS in Nadir and Left position (Appendix A.2.

It can be observed that there are no significant differences between the measured reflectance values for the HDS3000 in the Nadir and Left position, except for steel, since it is a very reflective material. In 


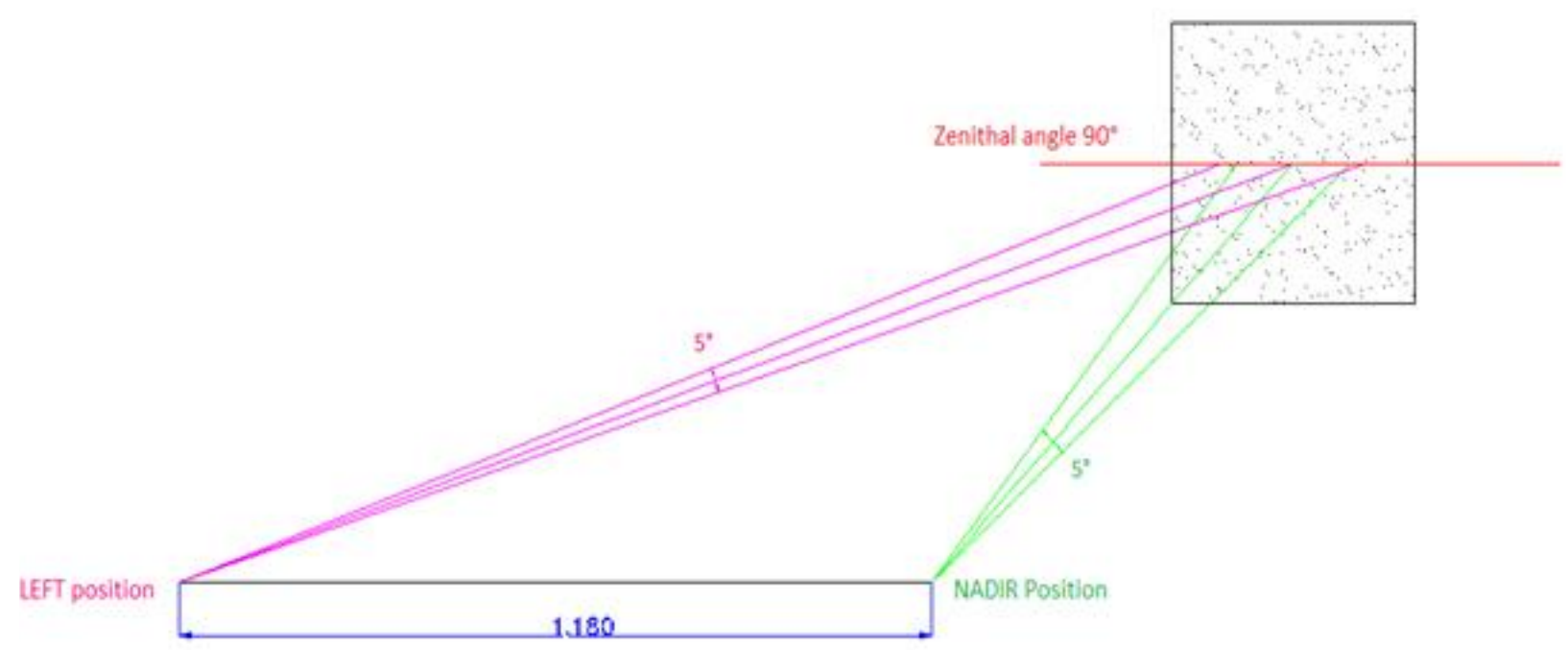

Figure 3. Geometric scheme of data acquisition.

\begin{tabular}{lcccccc}
\hline \multirow{2}{*}{ Sample } & \multicolumn{3}{c}{ HDS3000 } & \multicolumn{3}{c}{ HDS6100 } \\
\cline { 2 - 7 } & $I$ & $\sigma_{I}$ & $D$ & $I$ & $\sigma_{I}$ & $D$ \\
\hline Glass & 0.511 & 0.001 & 2.736 & 0.462 & 0.006 & 2.736 \\
Frosted glass & 0.517 & 0.007 & 2.775 & 0.444 & 0.020 & 2.729 \\
White lime plaster & 0.518 & 0.006 & 2.813 & 0.927 & 0.021 & 2.813 \\
Coloured lime plaster & 0.510 & 0.002 & 2.811 & 0.868 & 0.026 & 2.811 \\
Smooth cement plaster & 0.524 & 0.010 & 2.794 & 0.943 & 0.021 & 2.794 \\
Raw cement plaster & 0.514 & 0.001 & 2.792 & 0.824 & 0.019 & 2.792 \\
TFE & 0.455 & 0.003 & 2.799 & - & - & - \\
Steel & 0.606 & 0.058 & 2.826 & - & - & - \\
Brass & 0.661 & 0.019 & 2.780 & - & - & - \\
HDPE & 0.623 & 0.011 & 2.780 & 0.996 & 0.011 & 2.777 \\
PMMA & 0.433 & 0.004 & 2.781 & - & - & - \\
\hline
\end{tabular}

TABLE 2. Statistic report of the measurements in Nadir position.

\begin{tabular}{lcccccc}
\hline \multirow{2}{*}{ Sample } & \multicolumn{3}{c}{ HDS3000 } & \multicolumn{3}{c}{ HDS6100 } \\
\cline { 2 - 7 } & $I$ & $\sigma_{I}$ & $D$ & $I$ & $\sigma_{I}$ & $D$ \\
\hline Glass & 0.508 & 0.002 & 2.934 & 0.435 & 0.006 & 2.936 \\
Frosted glass & 0.517 & 0.007 & 2.976 & 0.465 & 0.020 & 2.978 \\
White lime plaster & 0.517 & 0.005 & 3.015 & 0.932 & 0.025 & 3.081 \\
Coloured lime plaster & 0.508 & 0.003 & 3.027 & 0.845 & 0.020 & 3.082 \\
Smooth cement plaster & 0.515 & 0.004 & 3.013 & 0.984 & 0.021 & 3.011 \\
Raw cement plaster & 0.515 & 0.005 & 3.000 & 0.823 & 0.019 & 3.008 \\
TFE & 0.454 & 0.003 & 3.017 & 0.096 & 0.069 & 3.015 \\
Steel & 0.417 & 0,008 & 3.065 & - & - & - \\
Brass & 0.414 & 0.008 & 3.071 & - & - & - \\
HDPE & 0.638 & 0.009 & 3.010 & 0.998 & 0.015 & 3.011 \\
PMMA & 0.480 & 0.030 & 3.070 & - & - & - \\
\hline
\end{tabular}

TABLE 3. Statistic report of the measurements in Left position. 
particular, a different behaviour can be observed for steel and brass compared to other materials; in fact, it is possible to detect a high difference in reflectivity between Nadir and Left.

The left position shows a minor range of reflectivity. This behaviour could be justified by the hypothesis that in Nadir, the reflectivity reaches values close to saturation, meaning the material is very reflective.

For other materials, such as smooth cement plaster, raw cement plaster, HDPE and PMMA, the difference could be justified by the roughness of the materials (Table 4).

Specifically in Figure 4, it can be observed that materials with a higher reflectivity, such as smooth cement plaster and, even more, HDPE, affect the signal saturation in HDS6100. This would also explain why for brass and steel, there is no reflectivity in HDS6100.

The HDS6100 manufacturer pointed out that the saturation process is attributable to the management software that filters the acquired data within welldefined ranges of reflectivity outside of which the data is considered as noise 30.

From data analysis, it can be noted that the data recorded by the HDS6100 are noisier than those recorded by the HDS3000, as already shown in Table 1. which, in the same experimental conditions, reports higher values of standard deviations for the HDS6100 31.

Moreover, the Table 2 also shows that the HDS3000 detects all the materials above mentioned discriminating them in a limited range of reflectance values (0.4-0.6), while the HDS6100, although it records in a wider range, exactly equal to the interval $(0-1)$, shows saturation for fewer materials, which would also justify the dispersion of values about the mean.

The implementation provided by the software (Leica Geosystems HDS Cyclone) considers, for the HDS6100, a maximum reference at the reflectivity of the Leica Geosystems targets (LGts) (Figure 5 and a probable minimum one in correspondence to amorphous materials (for example Teflon) and, therefore, there is no recording of data, above or below these values. This does not apply for the HDS3000 that has been set with a narrow range; everything that turns out to have a greater or lesser reflectance is recorded (target reflectance is equal to about 0.68 ).

\subsection{Relationship BETWEen REFLECTANCE AND CRYSTALLINITY VALUES ON TESTED MATERIALS}

Operating protocols of scanning were carefully planned in order to maximize the data reliability and accuracy. Special attention was paid to the reproducibility of survey operations, to the stability of scan boundary environmental conditions, to the environmental brightness and to the relative positioning of the TLS equipment and the scanned samples.
To evaluate the change in reflectance varying the incidence angle of the laser beam on the sample, the equipment has been positioned (as shown in Figure 1) on some discrete angles known from the Nadir to the left position, whereas the location of the sample remained constant.

The values of reflectance for each sample, varying the azimuthal angle, were detected in a preliminary data analysis; the Tables 3 and 4 show how these values are not substantially affected by the angle of incidence.

By observing the reflectance data, it is possible to deduce that for all scanned materials varying the azimuthal angle of incidence and being equal in every other experimental parameter, reflectance values change in a consistent way with the degree of crystallinity of the scanned object.

Since it is not able to more accurately assess the degree of crystallinity of the materials under investigation at this phase of the research, we have taken into consideration the values provided by the manufacturers, that are well known in the scientific literature.

In overall terms, the following figures show the linear trend between the collected average reflectance and the degree of crystallinity of the materials investigated by the HDS3000 and the HDS6100 instruments (Figures 6-7).

The least squares regression line confirms the good correlation between parameters, which allows us to state that the most crystalline materials have a higher reflectance than the amorphous ones (Figures 8- 9).

We can also observe the consistency of the data pointed out by the two lasers; in fact, for the HDS6100, all materials (except those in saturation) show the same behaviour.

\section{Discussion}

The results shown in the previous paragraphs show that, in addition to numerous parameters, such as colour, roughness, humidity, temperature, etc., the first crystal layers and Bravais lattices of the scanned material also influence the reflectance value related to the interaction of the laser pulse generated by the TLS.

As already experienced by Logiurato et al. (2006) 28] low power laser rays, thanks to their nature of "coherent" light, are able to generate bright interference phenomena on the very first lattice layers of crystalline solids, producing a variety of optical diffraction processes in accordance with the Bragg's law. Therefore, by an accurate analysis of the reflectance, a correlation between these data and the qualitative chemical identifying of scanned materials could be assumed.

A further aspect to be taken into consideration concerns the interval of the reflectance set in the instruments and software of data acquisition. Indeed, the production subsequent to the HDS3000, namely ScanStation2 and ScanStation C10, P20, P30/40 (for 


\begin{tabular}{|c|c|c|c|c|c|c|c|c|c|}
\hline \multirow[t]{2}{*}{ Material } & \multicolumn{2}{|c|}{$\begin{array}{l}\text { Minimum } \\
\text { reflectance }\end{array}$} & \multicolumn{2}{|c|}{$\begin{array}{l}\text { Maximum } \\
\text { reflectance }\end{array}$} & \multicolumn{2}{|c|}{$\begin{array}{l}\text { Reflectance } \\
\text { range } \\
\text { (max-min) }\end{array}$} & \multirow[t]{2}{*}{$\begin{array}{c}\text { Difference } \\
\text { between } \\
\text { Nadir and } \\
\text { Left range }\end{array}$} & \multirow[t]{2}{*}{$\begin{array}{l}\text { Mean } \\
\text { reflectance } \\
\text { in Nadir } \\
\text { and Left }\end{array}$} & \multirow{2}{*}{$\begin{array}{c}\text { Mean } \\
\text { range of } \\
\text { reflectance } \\
\text { in Nadir } \\
\text { and Left }\end{array}$} \\
\hline & $\mathrm{N}$ & $\mathrm{L}$ & $\mathrm{N}$ & $\mathrm{L}$ & $\mathrm{N}$ & $\mathrm{L}$ & & & \\
\hline Glass & 0.503 & 0.493 & 0.515 & 0.512 & 0.012 & 0.019 & 0.007 & 0.509 & 0.015 \\
\hline Ground Glass & 0.513 & 0.513 & 0.584 & 0.584 & 0.071 & 0.071 & 0.000 & 0.548 & 0.071 \\
\hline White lime plaster & 0.513 & 0.512 & 0.539 & 0.538 & 0.026 & 0.026 & 0.000 & 0.526 & 0.026 \\
\hline Coloured lime plaster & 0.492 & 0.491 & 0.514 & 0.513 & 0.022 & 0.023 & 0.001 & 0.503 & 0.022 \\
\hline Smooth cement plaster & 0.513 & 0.485 & 0.542 & 0.538 & 0.029 & 0.053 & 0.023 & 0.528 & 0.041 \\
\hline Row cement plaster & 0.512 & 0.481 & 0.520 & 0.537 & 0.008 & 0.056 & 0.48 & 0.516 & 0.032 \\
\hline TFE & 0.433 & 0.432 & 0.477 & 0.476 & 0.044 & 0.044 & 0.000 & 0.455 & 0.044 \\
\hline Steeel & 0.483 & 0.387 & 0.683 & 0.516 & 0.200 & 0.129 & -0.071 & 0.583 & 0.164 \\
\hline Brass & 0.408 & 0.400 & 0.683 & 0.479 & 0.275 & 0.080 & -0.195 & 0.545 & 0.177 \\
\hline HDPE & 0.610 & 0.621 & 0.646 & 0.676 & 0.036 & 0.055 & 0.019 & 0.628 & 0.045 \\
\hline PMMA & 0.386 & 0.423 & 0.578 & 0.589 & 0.192 & 0.166 & -0.025 & 0.482 & 0.179 \\
\hline
\end{tabular}

TABLE 4. Range of variation of reflectance between Nadir and Left position for HDS3000 data.

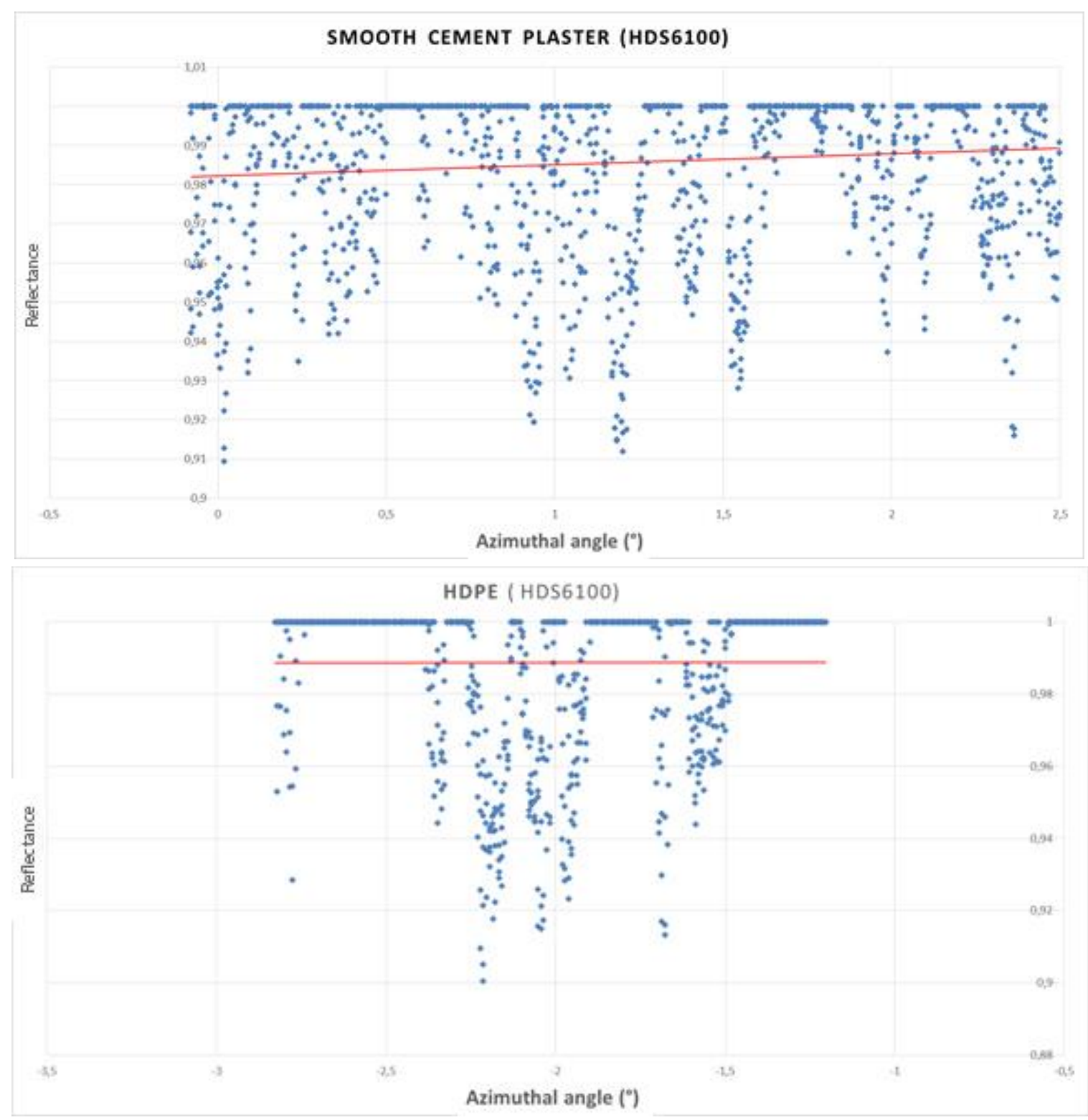

(a)

(b)

FigURE 4. Saturation reflectance diagram obtained by the use of HDS6100 for smooth cement plaster (a) and $\operatorname{HDPE}(\mathrm{b})$. 

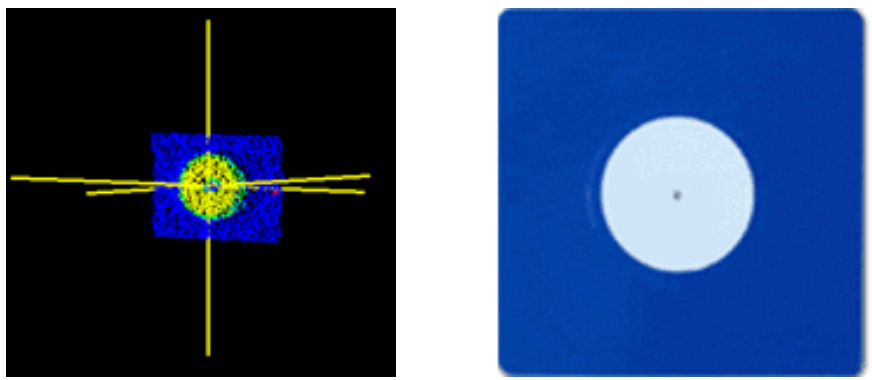

TLS

HDS3000

HDS6100

Scan Station C10

\section{Reflectance}

0.68

0.98

0.97

FiguRE 5. Square planar target $\left(3^{\prime \prime} \times 3^{\prime \prime}\right)$ and reflectance value on the targets in relation to TLS.

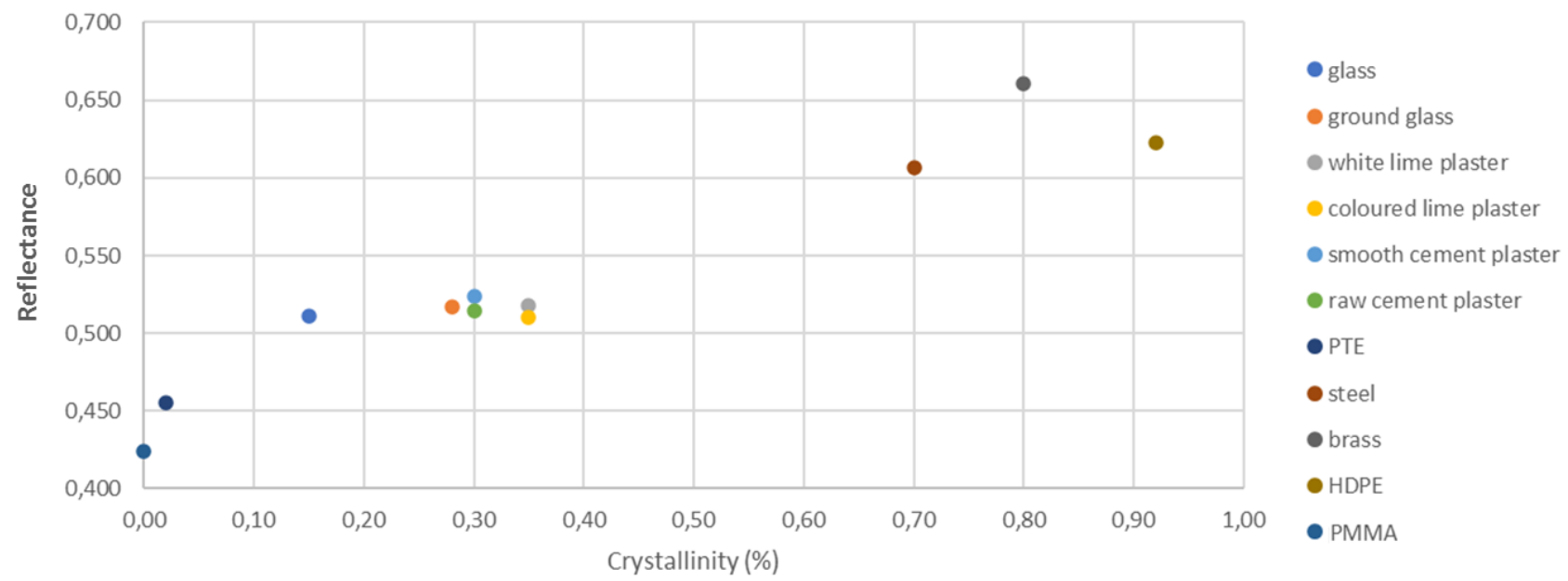

FiguRE 6. Reflectance values varying the degree of crystallinity of materials scanned by the HDS3000 in Nadir position.

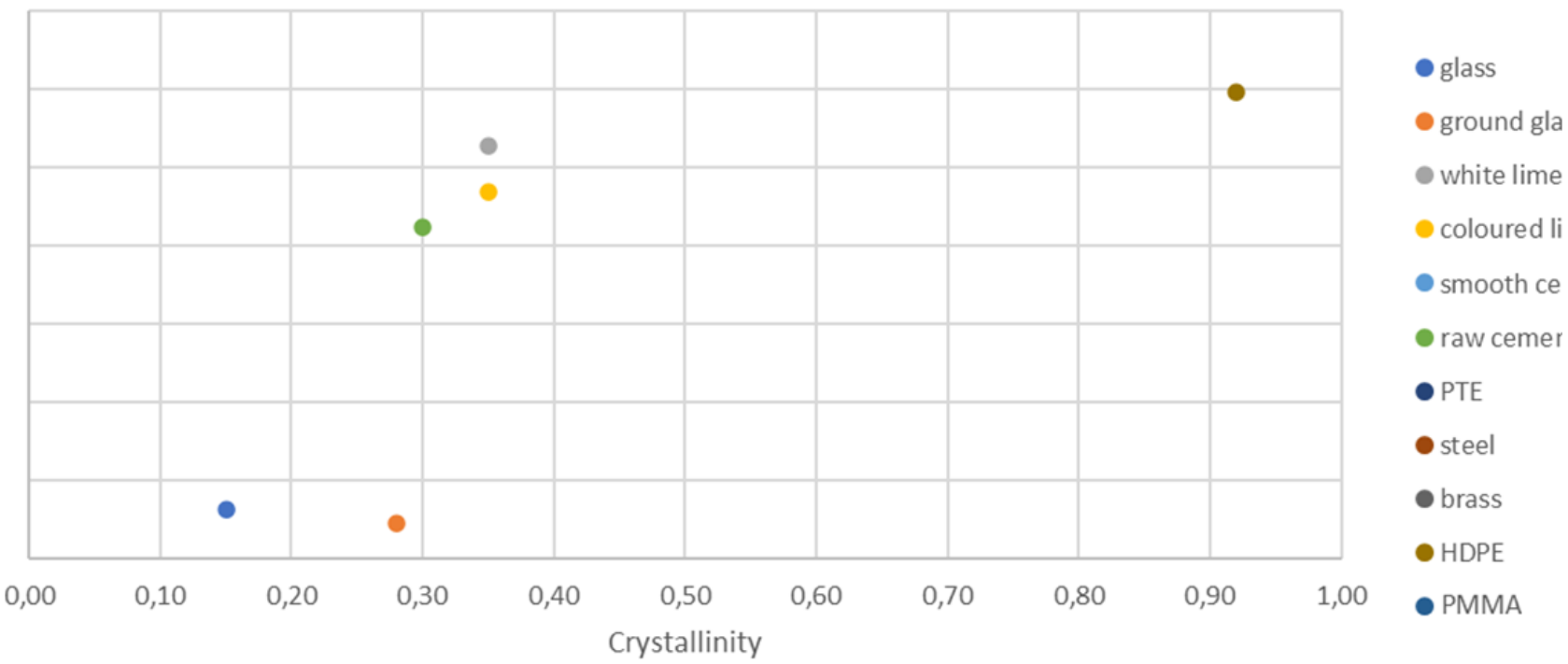

FIGURE 7. Reflectance values varying the degree of crystallinity of materials scanned by the HDS6100 in Nadir position. 


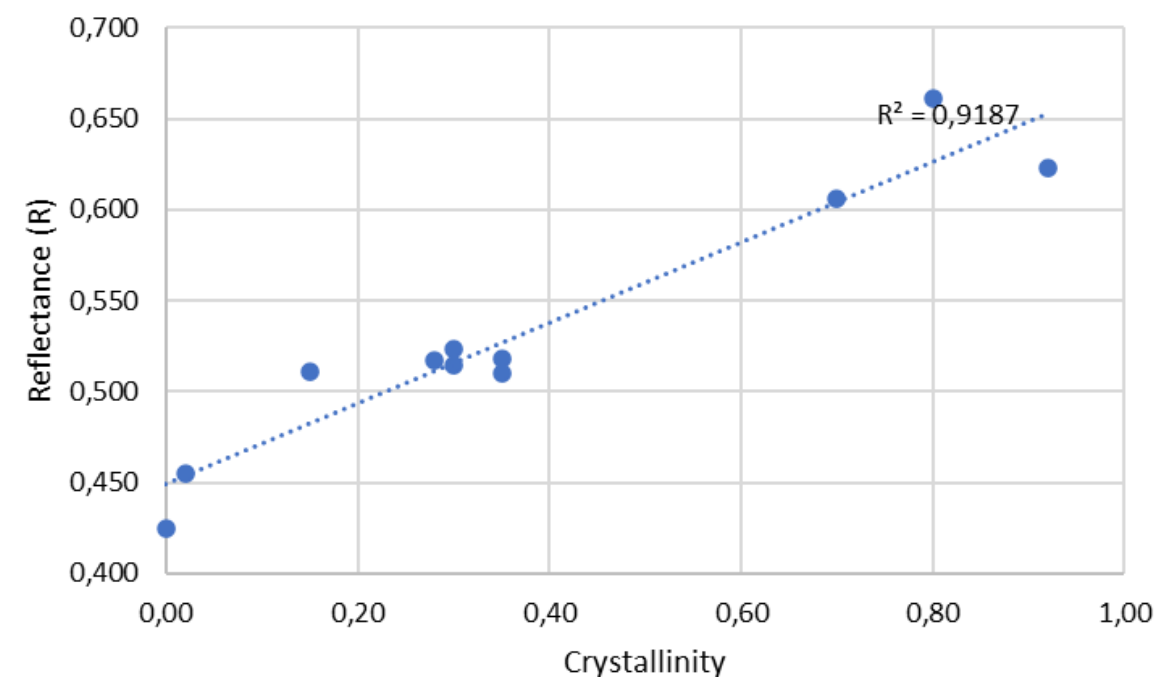

FiguRE 8. Reflectance values represented by linear least squares regression (HDS3000).

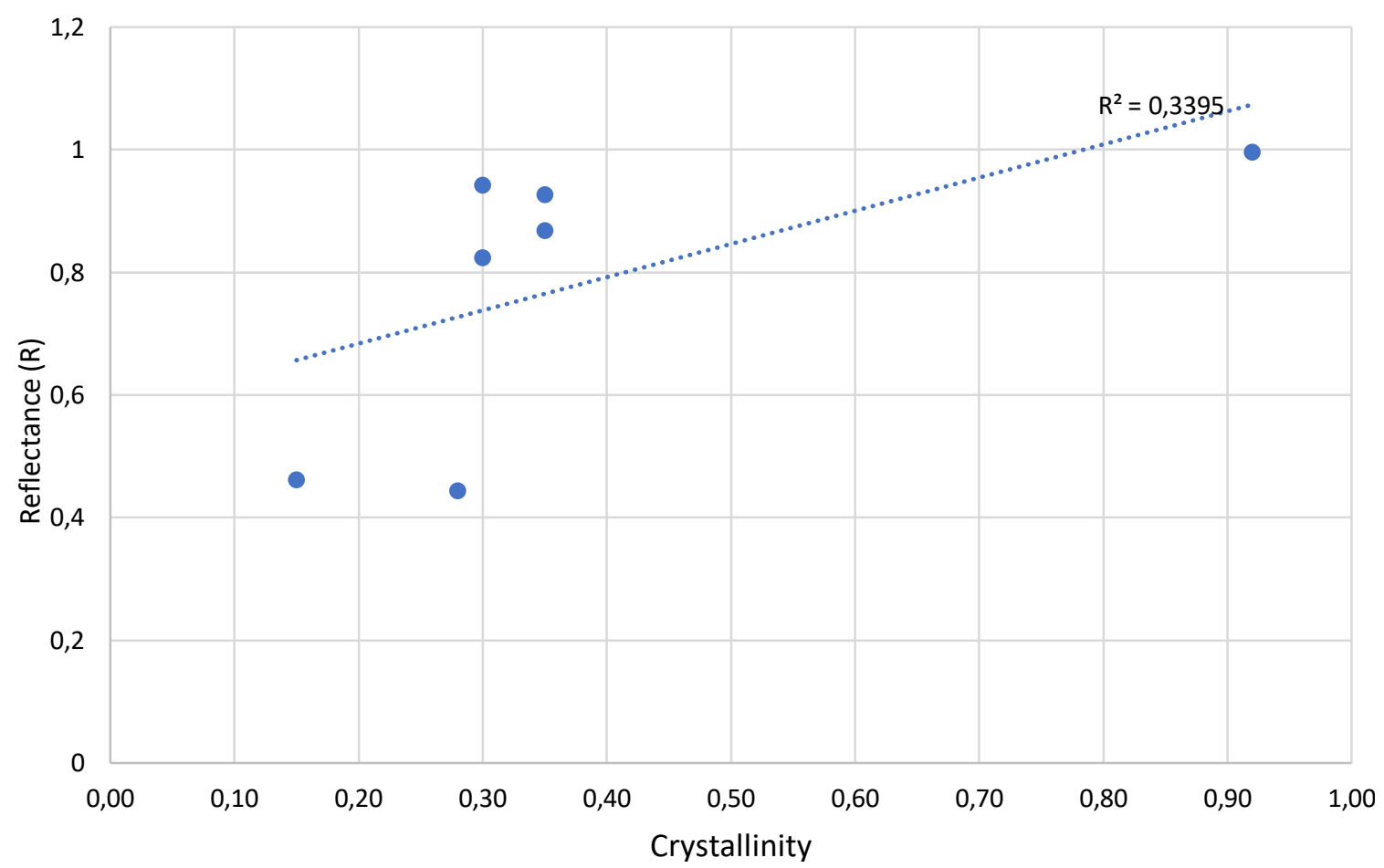

Figure 9. Reflectance values represented by linear least squares regression (HDS6100).

\begin{tabular}{cccc}
\hline Operation principle & TLS instrument & Scan rate $(\mathrm{pt} / \mathrm{sec})$ & Range reflectance \\
\hline \multirow{3}{*}{ TOF } & HDS3000 & 4000 & $0.38-0.68$ \\
& ScanStation C10 & 50000 & $0-1$ \\
\multirow{3}{*}{ Phase shift } & P20 & 1000000 & $0-1$ \\
& HDS4500 & 500000 & $0-1$ \\
& HDS6100/6200 & 500000 & $0-1$ \\
\hline
\end{tabular}

TABLE 5. Scan rate and range of reflectance for different TLS. 
example, the rough cement plaster has an average value of reflectance of 0.7842 ), has significantly increased the scanning speed and has a wider range of reflectance, between $(0-1)$ (Table 5 ).

In the case of the HDS4500, the LGts could not be used because they were not recognized, and, for this reason, the Black \& White Target (recognizable at low distances) were used. In the case of the HDS6100/6200, LGts are recognized, but they have high reflectance values (Table 5). The table below shows a summary of the scan rate and the range of reflectance in the different instruments.

\section{Conclusion}

In this research paper, it has been demonstrated that the incident light beam is much more refracted by materials with a higher degree of crystallinity, compared to less crystalline or amorphous materials; this could lead to a quick identification of materials. Furthermore, since the crystallinity of the surface is influenced by external phenomena, such as increased salinity, humidity, etc. (and all those phenomena and structures subject to agents that modify the surface crystallinity) it may be possible to verify the increase in degradation phenomena linked to these factors for materials that are a part of an architectural, painting or archaeological element.

Therefore, the possibility of evaluating the crystalline nature of materials opens up new perspectives for a rapid field investigation of the various elements using only geometric and radiometric information from a TLS survey. Moreover, it would be possible to carry out TLS monitoring to verify the state of conservation of some elements.

Further developments of this research are aimed at verifying the results of samples subjected to salinity treatments, increase in humidity and temperature variation and external aggression phenomena or multitemporal investigations on the same materials.

\section{REFERENCES}

[1] J. Shan, C. K. Toth. Topographic laser ranging and scanning: principles and processing. CRC press, 2018.

[2] M. Pepe, D. Costantino, A. Restuccia Garofalo. An efficient pipeline to obtain 3D model for HBIM and structural analysis purposes from 3D point clouds. Applied Sciences 10(4):1235, 2020. DOI:10.3390/app10041235

[3] R. I. Hartley, A. Zisserman. Multiple View Geometry in Computer Vision. Cambridge University Press, 2nd edn., 2004.

[4] S. Soudarissanane, R. Lindenbergh, M. Menenti, $P$. Teunissen. Scanning geometry: Influencing factor on the quality of terrestrial laser scanning points. ISPRS journal of photogrammetry and remote sensing 66(4):389 - 399, 2011. DOI:10.1016/j.isprsjprs.2011.01.005

[5] K. Määttä, J. Kostamovaara, R. Myllylä. Profiling of hot surfaces by pulsed time-of-flight laser range finder techniques. Applied Optics 32(27):5334 - 5347, 1993. DOI:10.1364/AO.32.005334.
[6] F. de Asís López, C. Ordóñez, J. Roca-Pardiñas, S. García-Cortés. Point cloud comparison under uncertainty. Application to beam bridge measurement with terrestrial laser scanning. Measurement 51:259 264, 2014. DOI:10.1016/j.measurement.2014.02.013

[7] K. Van Balen, E. Verstrynge. Structural Analysis of Historical Constructions: Anamnesis, Diagnosis, Therapy, Controls: Proceedings of the 10th International Conference on Structural Analysis of Historical Constructions (SAHC, Leuven, Belgium, 13-15 September 2016). CRC Press, 2016.

[8] N. Pfeifer, C. Briese. Geometrical aspects of airborne laser scanning and terrestrial laser scanning. International Archives of Photogrammetry, Remote Sensing and Spatial Information Sciences 36(3/W52):311 - 319, 2007.

[9] F. Coren, P. Sterzai. Radiometric correction in laser scanning. International Journal of Remote Sensing 27(15):3097 - 3104, 2006. DOI:10.1080/01431160500217277

[10] D. Akca. Matching of 3D surfaces and their intensities. ISPRS Journal of Photogrammetry and Remote Sensing 62(2):112 - 121, 2007. DOI:10.1016/j.isprsjprs.2006.06.001.

[11] M. Bureš, S. Martirosov, J. Polcar. A novel projection algorithm for production layout extraction from point clouds. Acta Polytechnica 59(3):203 - 210, 2019. DOI:10.14311/AP.2019.59.0203

[12] T. Aschoff, M. Thies, H. Spiecker. Describing forest stands using terrestrial laser-scanning. International Archives of Photogrammetry, Remote Sensing and Spatial Information Sciences 35(5):237 - 241, 2004.

[13] N. J. Rosser, S. A. Dunning, D. N. Petley. Multi-spectral terrestrial laser scanning for interpreting the controls on and changes to unstable rock faces 9:07021, 2007.

[14] N. Pfeifer, B. Höfle, C. Briese, et al. Analysis of the backscattered energy in terrestrial laser scanning data. The International Archives of the Photogrammetry, Remote Sensing and Spatial Information Sciences 37:1045 - 1052, 2008.

[15] D. D. Lichti, B. R. Harvey. The effects of reflecting surface material properties on time-of-flight laser scanner measurements. In Proceedings of the Symposium on Geospatial Theory, Processing and Applications, pp. 1 - 9. Ottawa, Canada, 2002.

[16] A. Masiero, D. Costantino. TLS for detecting small damages on a building façade. International Archives of the Photogrammetry, Remote Sensing and Spatial Information Sciences XLII-2/W11:831 - 836, 2019. DOI:10.5194/isprs-archives-XLII-2-W11-831-2019.

[17] K. H. Thiel, A. Wehr. Performance capabilities of laser-scanners-an overview and measurement principle analysis. International Archives of Photogrammetry, Remote Sensing and Spatial Information Sciences 36(8):14 - 18, 2004.

[18] W. Boehler, M. B. Vicent, A. Marbs. Investigating laser scanner accuracy. The International Archives of Photogrammetry, Remote Sensing and Spatial Information Sciences 34(5):696 - 701, 2003. 
[19] T. Kersten, K. Mechelke, M. Lindstaedt, H. Sternberg. Geometric accuracy investigations of the latest terrestrial laser scanning systems. In Proceedings of the FIG Working Week, Integrating the Generations, TS 5G-Calibration of Instruments, pp. 1-16. Stockholm, Sweden, 2008.

[20] A. Kukko, S. Kaasalainen, P. Litkey. Effect of incidence angle on laser scanner intensity and surface data. Applied optics 47(7):986 - 992, 2008. DOI:10.1364/AO.47.000986

[21] N. Pfeifer, P. Dorninger, A. Haring, H. Fan. Investigating terrestrial laser scanning intensity data: quality and functional relations. In Proceedings of the 8th International Conference on Optical 3-D Measurement Techniques, pp. 328 - 337. Zurich, Sweitzerland, 2007.

[22] J. U. H. Eitel, L. A. Vierling, D. S. Long. Simultaneous measurements of plant structure and chlorophyll content in broadleaf saplings with a terrestrial laser scanner. Remote sensing of Environment 114(10):2229 2237, 2010. DOI:10.1016/j.rse.2010.04.025

[23] S. Kaasalainen, A. Krooks, A. Kukko, H. Kaartinen. Radiometric calibration of terrestrial laser scanners with external reference targets. Remote Sensing 1(3):144 - 158, 2009. DOI:10.3390/rs1030144

[24] M. A. Balduzzi, D. Van der Zande, J. Stuckens, et al. The properties of terrestrial laser system intensity for measuring leaf geometries: a case study with conference pear trees (Pyrus Communis). Sensors 11(2): 1657 1681, 2011. DOI:10.3390/s110201657.

[25] S. Soudarissanane, R. Lindenbergh, M. Menenti, P. J. G. Teunissen. Incidence angle influence on the quality of terrestrial laser scanning points. In Proceedings of ISPRS Workshop Laserscanning 2009, vol. 38, pp. 183 - 188. Paris, France, 2009.

[26] D. Costantino, M. G. Angelini. Qualitative and quantitative evaluation of the luminance of laser scanner radiation for the classification of materials. International Archives of the Photogrammetry, Remote Sensing and Spatial Information Sciences, Strasbourg, France XL-5/W2:207 - 212.

[27] M. P. Groover. Fundamentals of modern manufacturing: Materials processes, and systems. John Wiley \& Sons, 2007.

[28] F. Logiurato, L. M. Gratton, S. Oss. Un semplice dispositivo per la visualizzazione tridimensionale del comportamento della luce. Giornale Di Fisica 47(4):301 - 309, 2006. DOI:10.1393/gdf/i2006-10014-6.

[29] S. Kaasalainen, A. Jaakkola, M. Kaasalainen, et al. Analysis of incidence angle and distance effects on terrestrial laser scanner intensity: Search for correction methods. Remote Sensing 3(10):2207 - 2221, 2011. DOI: $10.3390 / \mathrm{rs} 3102207$

[30] T. Voegtle, S. Wakaluk. Effects on the measurements of the terrestrial laser scanner HDS 6000 (Leica) caused by different object materials. vol. 38 , pp. $68-74$. Paris, France, 2009.

[31] D. Costantino, M. G. Angelini, G. Caprino. Rapid approach of integrated survey for the conservative analysis of pictures. In XXI International CIPA Symposium, pp. 1 - 6. Athens, Greece, 2007. 


\section{A. Appendices}

A.1. Appendix 1: Main features of the TLS used for testing: HDS3000 And HDS6100

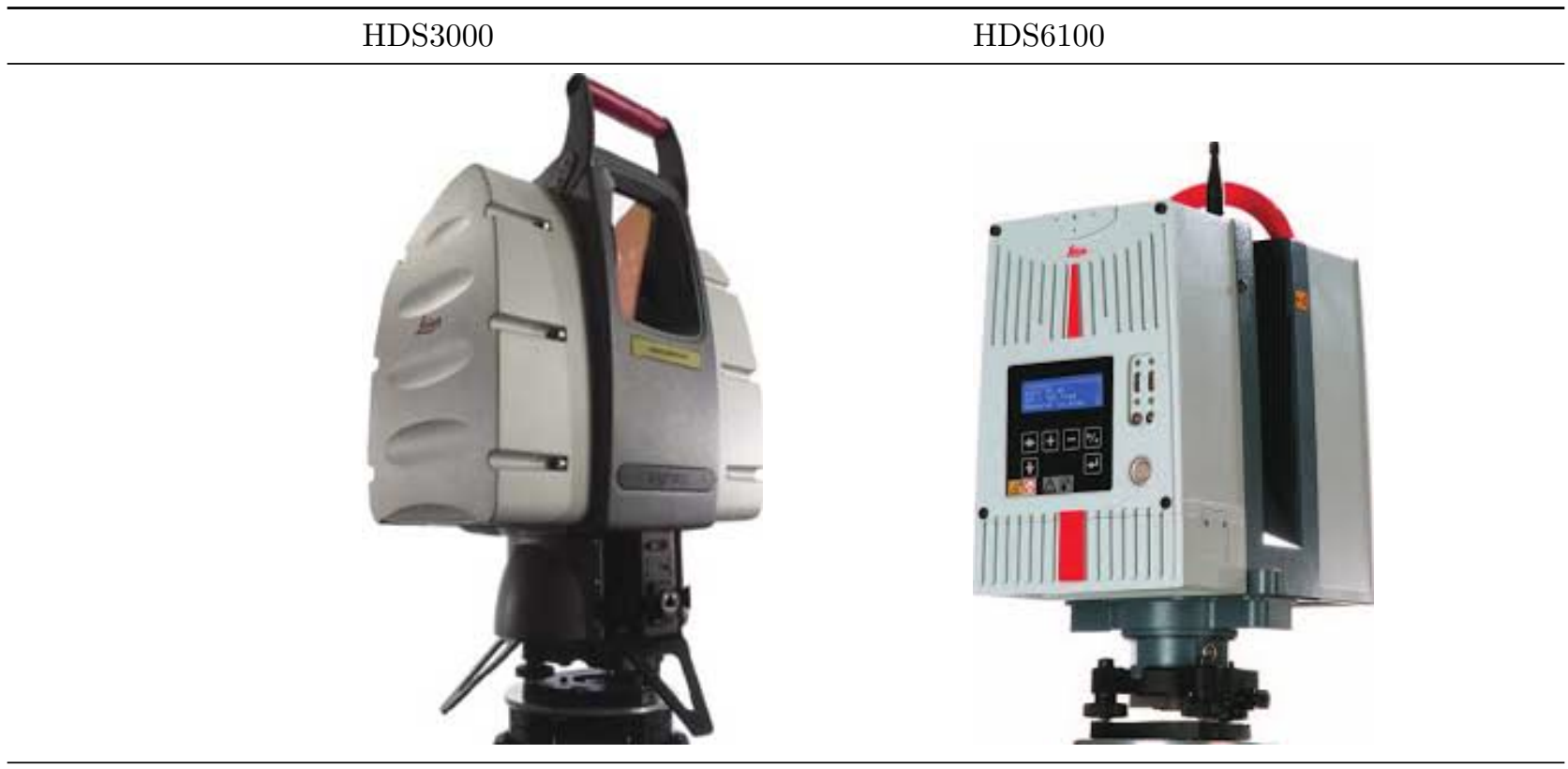

\begin{tabular}{|c|c|c|}
\hline Instrument type & $\begin{array}{l}\text { High-speed, high-accuracy laser radar } \\
\text { TYPE scanner with } 360^{\circ} \times 270^{\circ} \text { field-of- } \\
\text { view }\end{array}$ & $\begin{array}{l}\text { Compact, phase-based, dual-axis sens- } \\
\text { ing, ultra-high speed laser scanner, with } \\
\text { survey-grade accuracy and full field-of- } \\
\text { view }\end{array}$ \\
\hline $\begin{array}{l}\text { Accuracy of single } \\
\text { measurement }\end{array}$ & $\begin{array}{l}\text { Position: } 6 \mathrm{~mm} \\
\text { Distance: } 4 \mathrm{~mm} \\
\text { Angle (horizontal): } 60 \text { micro-radians } \\
\text { Angle (vertical): } 60 \text { micro-radians }\end{array}$ & $\begin{array}{l}\text { Position: } 5 \mathrm{~mm}, 1 \mathrm{~m} \text { to } 25 \mathrm{~m} \text { range; } 9 \mathrm{~mm} \\
\text { to } 50 \mathrm{~m} \text { range } \\
\text { Distance: } \leq 2 \mathrm{~mm} \text { at } 90 \% \text { albedo up to } \\
25 \mathrm{~m} ; \leq 3 \mathrm{~mm} \text { at } 18 \% \text { albedo up to } 25 \mathrm{~m} \\
\leq 3 \mathrm{~mm} \text { at } 90 \% \text { albedo up to } 50 \mathrm{~m} ; \leq \\
5 \mathrm{~mm} \text { at } 18 \% \text { albedo up to } 50 \mathrm{~m} \\
\text { Angle: } \\
\text { (Horizontal/vertical) } 125 \mu \mathrm{rads} / 125 \mu \mathrm{rads} \\
\text { ( } 7.9 \mathrm{mgon} / 7.9 \mathrm{mgon} \text { ) one sigma }\end{array}$ \\
\hline Spot size & $\leq 6 \mathrm{~mm}$ from $0-50$ meters & $\begin{array}{l}3 \mathrm{~mm} \text { at exit (based on Gaussian def- } \\
\text { inition) }+0.22 \mathrm{mrad} \text { divergence; } 8 \mathrm{~mm} \\
@ 25 \mathrm{~m} ; 14 \mathrm{~mm} @ 50 \mathrm{~m} \text {; }\end{array}$ \\
\hline Scan Rate & $\begin{array}{l}\text { Up to } 1800 \text { points/second (Maximum } \\
\text { scan rate dependent on scan resolution } \\
\text { and selected field-of-view) }\end{array}$ & $\begin{array}{l}\text { Up to } 508,000 \text { points/sec, maximum in- } \\
\text { stantaneous rate }\end{array}$ \\
\hline Range & $\begin{array}{l}\text { Optimal effective range: } 1 \mathrm{~m}-100 \mathrm{~m} \text {; } \\
\text { To } 10 \% \text { reflectivity targets: up to } 100 \mathrm{~m} \\
\text { (typical) }\end{array}$ & $\begin{array}{l}79 \mathrm{~m} \text { ambiguity interval } 79 \mathrm{~m} @ 90 \% ; 50 \mathrm{~m} \\
\text { @18\% albedo }\end{array}$ \\
\hline Target accuracy & $1.5 \mathrm{~mm}$ & $2 \mathrm{~mm}$ \\
\hline
\end{tabular}

TABLE 6. Main features of the TLS used for testing: HDS3000 and HDS6100. 
A.2. Appendix 2: Reflectance value in Nadir and Left position for Different MATERIALS
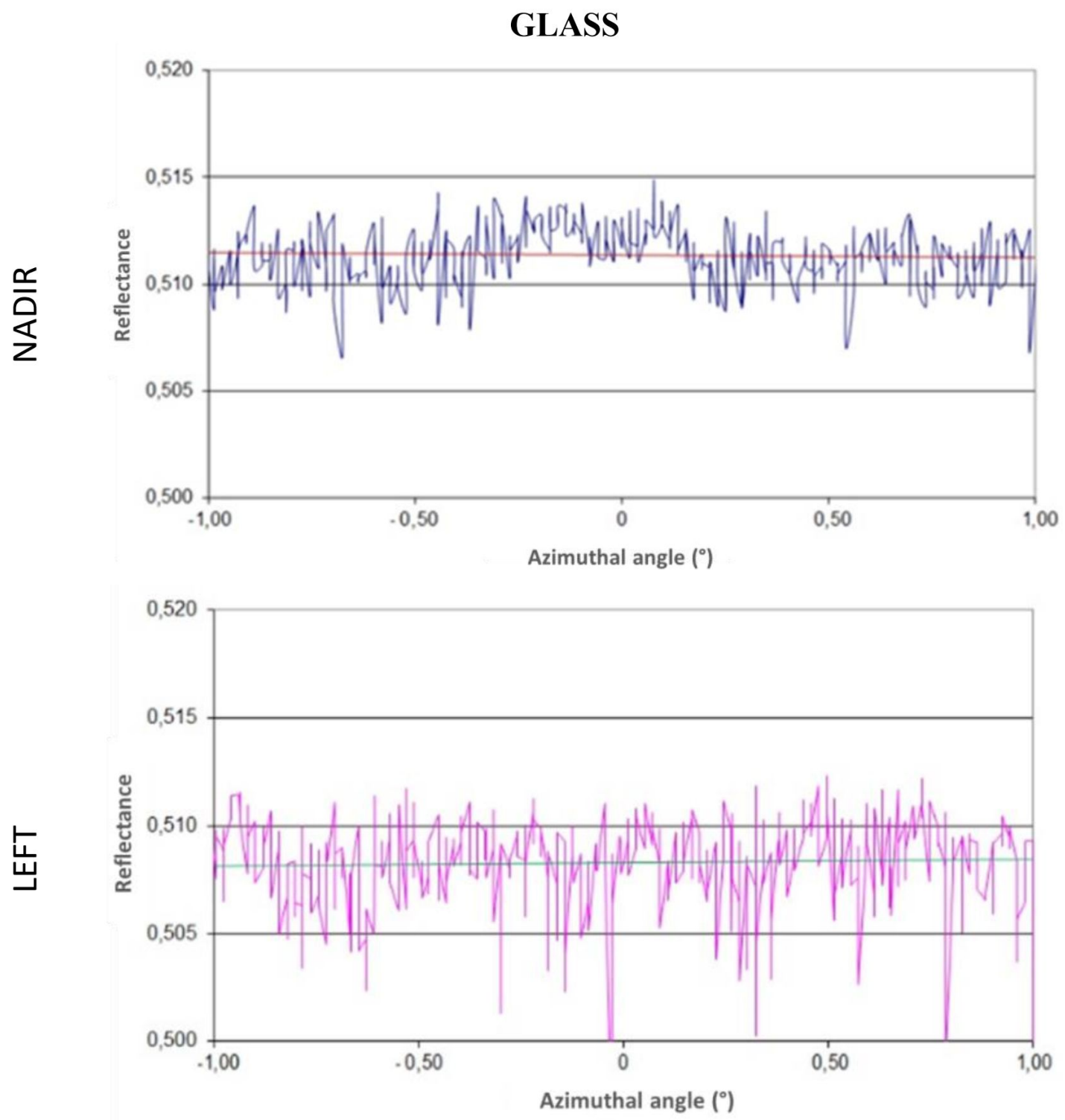

FiguRE 10. Glass reflectance value at different azimuth for Nadir and Left position. 


\section{GROUND GLASS}
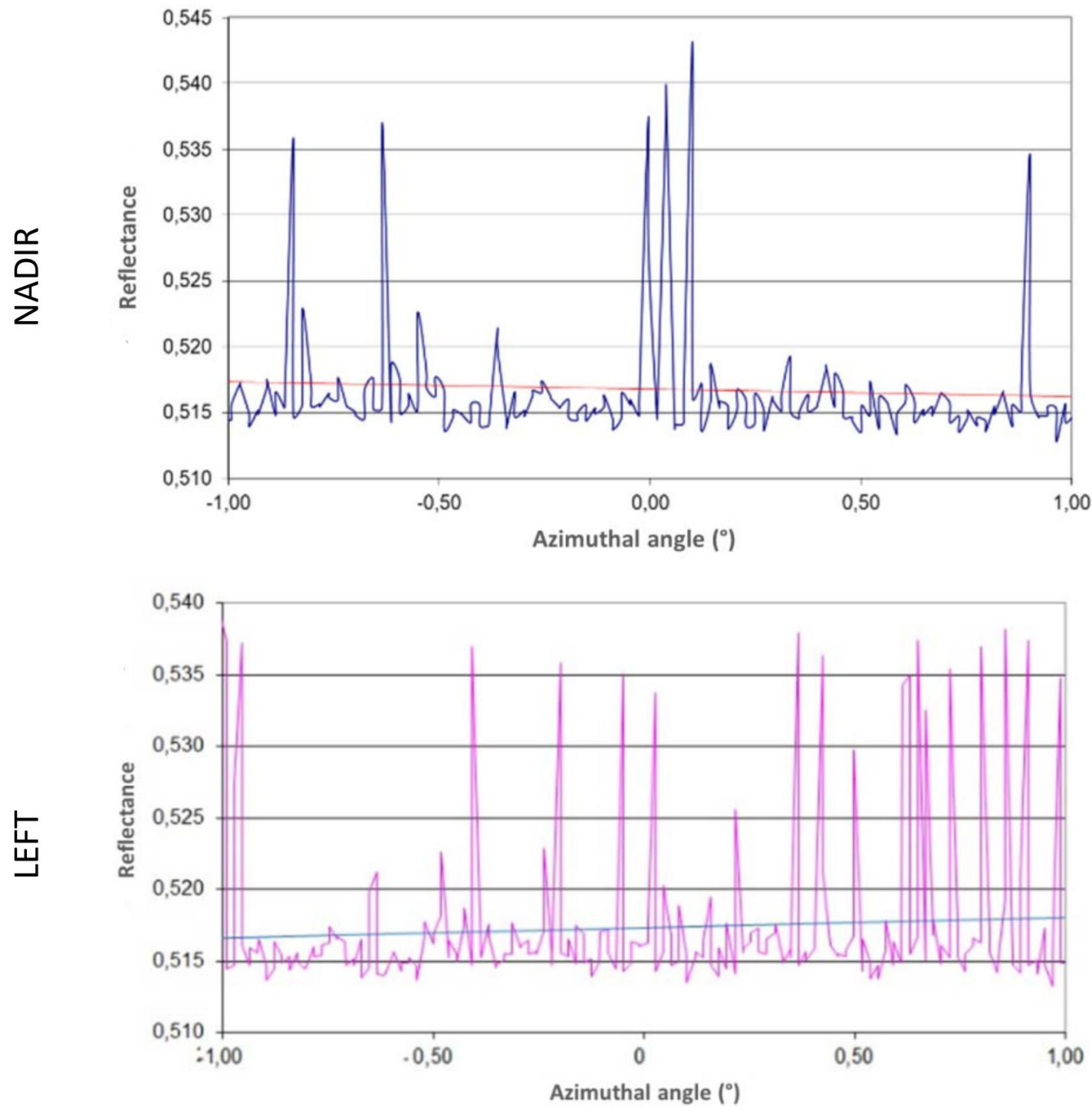

FiguRE 11. Groud Glass reflectance value at different azimuth for Nadir and Left position. 


\section{WHITE LIME PLASTER}
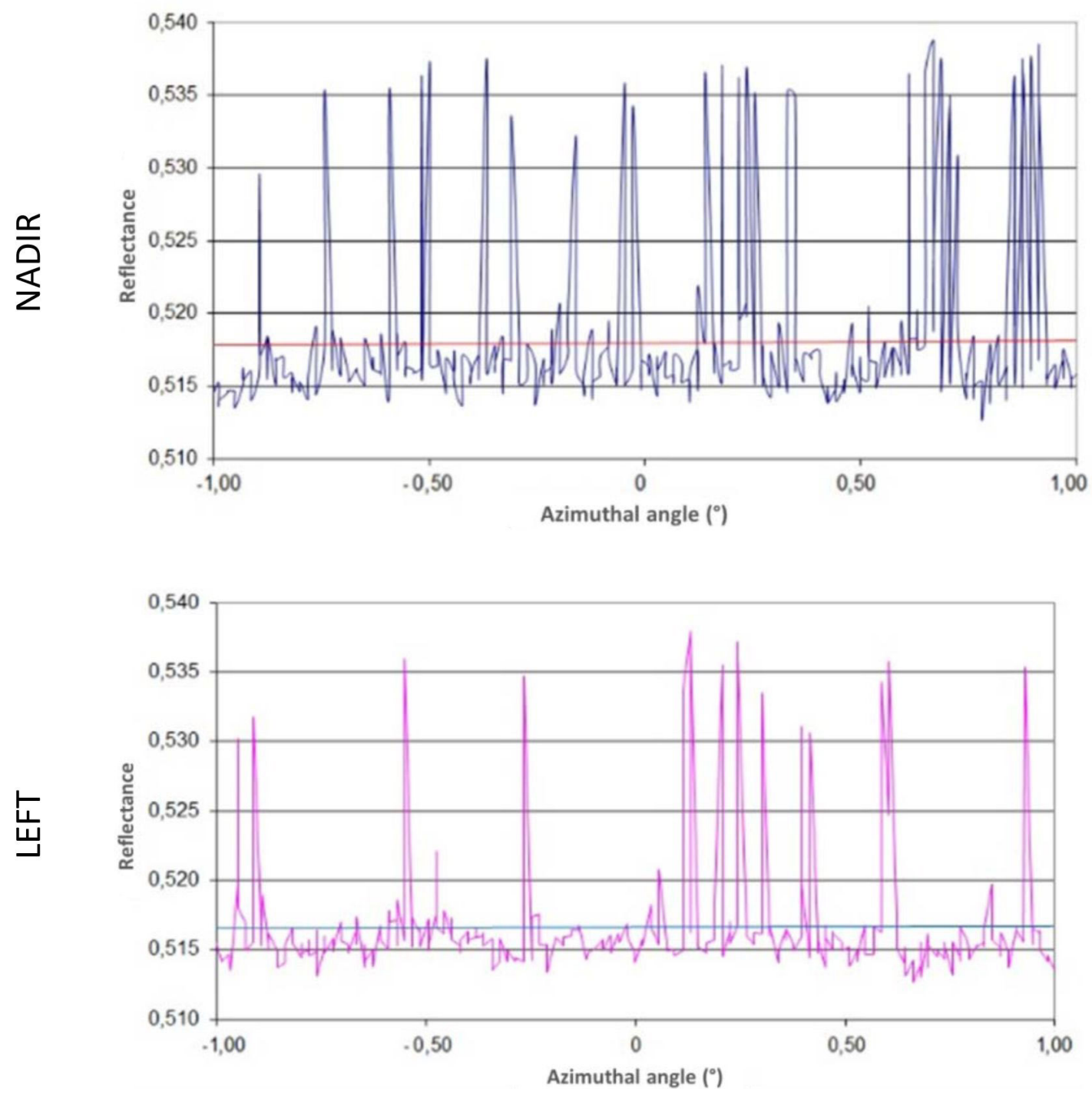

FIGURE 12. White lime plaster reflectance value at different azimuth for Nadir and Left position. 


\section{COLOURED LIME PLASTER}
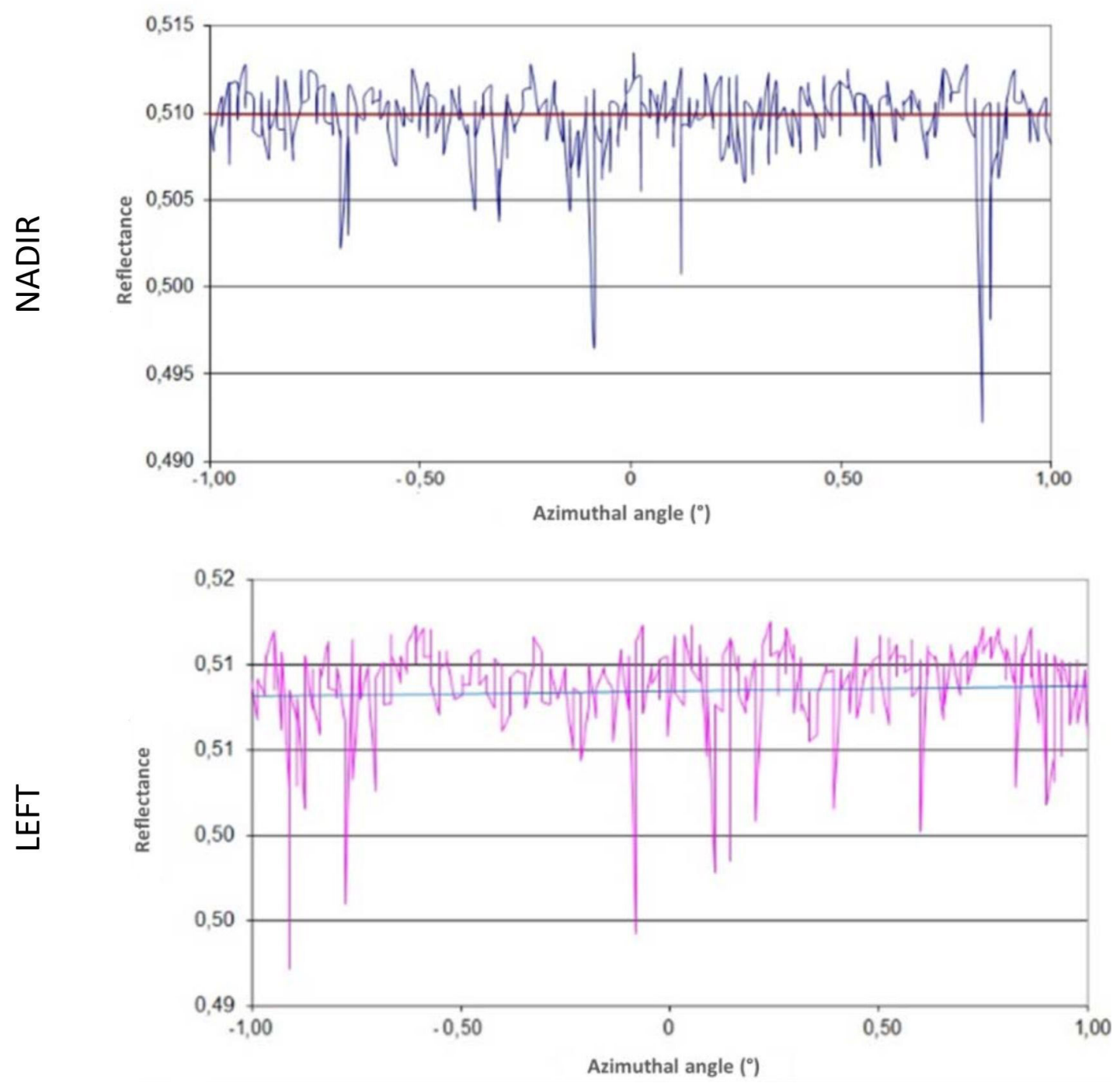

FiguRE 13. Coloured lime plaster reflectance value at different azimuth for Nadir and Left position. 


\section{SMOOTH CEMENT PLASTER}
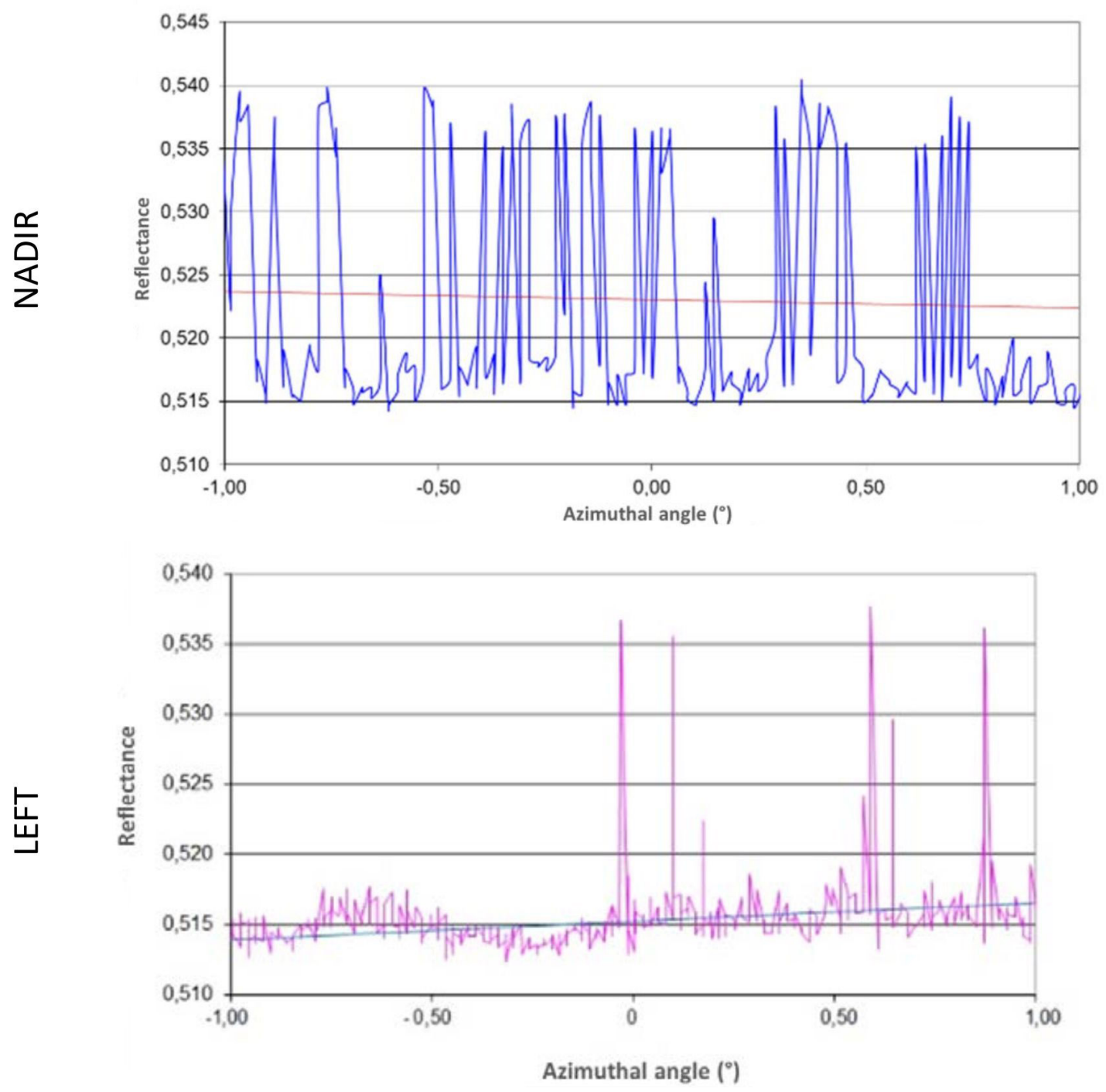

FigURE 14. Smooth cement plaster reflectance value at different azimuth for Nadir and Left position. 


\section{RAW CEMENT PLASTER}
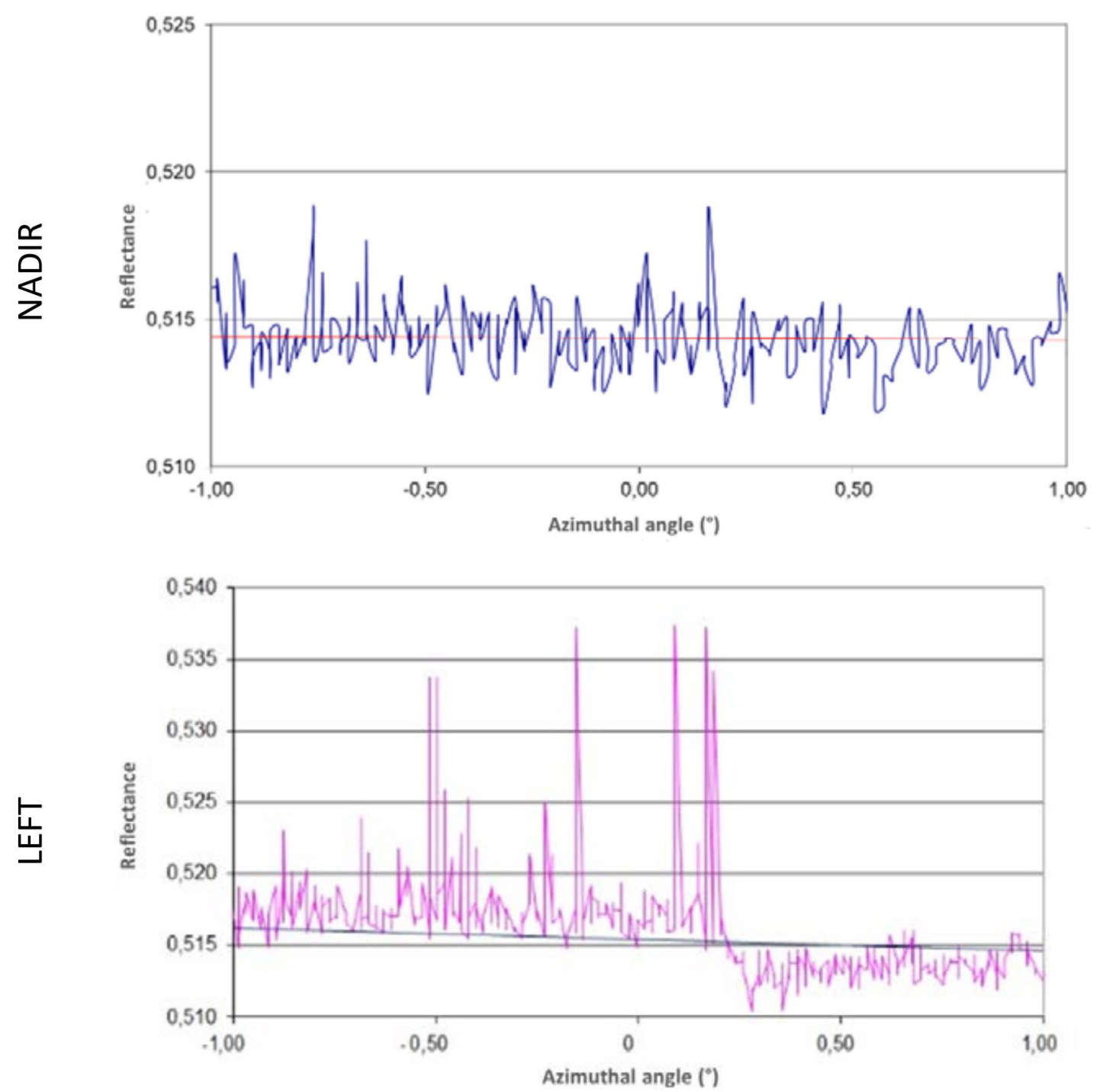

FiguRE 15. Raw cement plaster reflectance value at different azimuth for Nadir and Left position. 

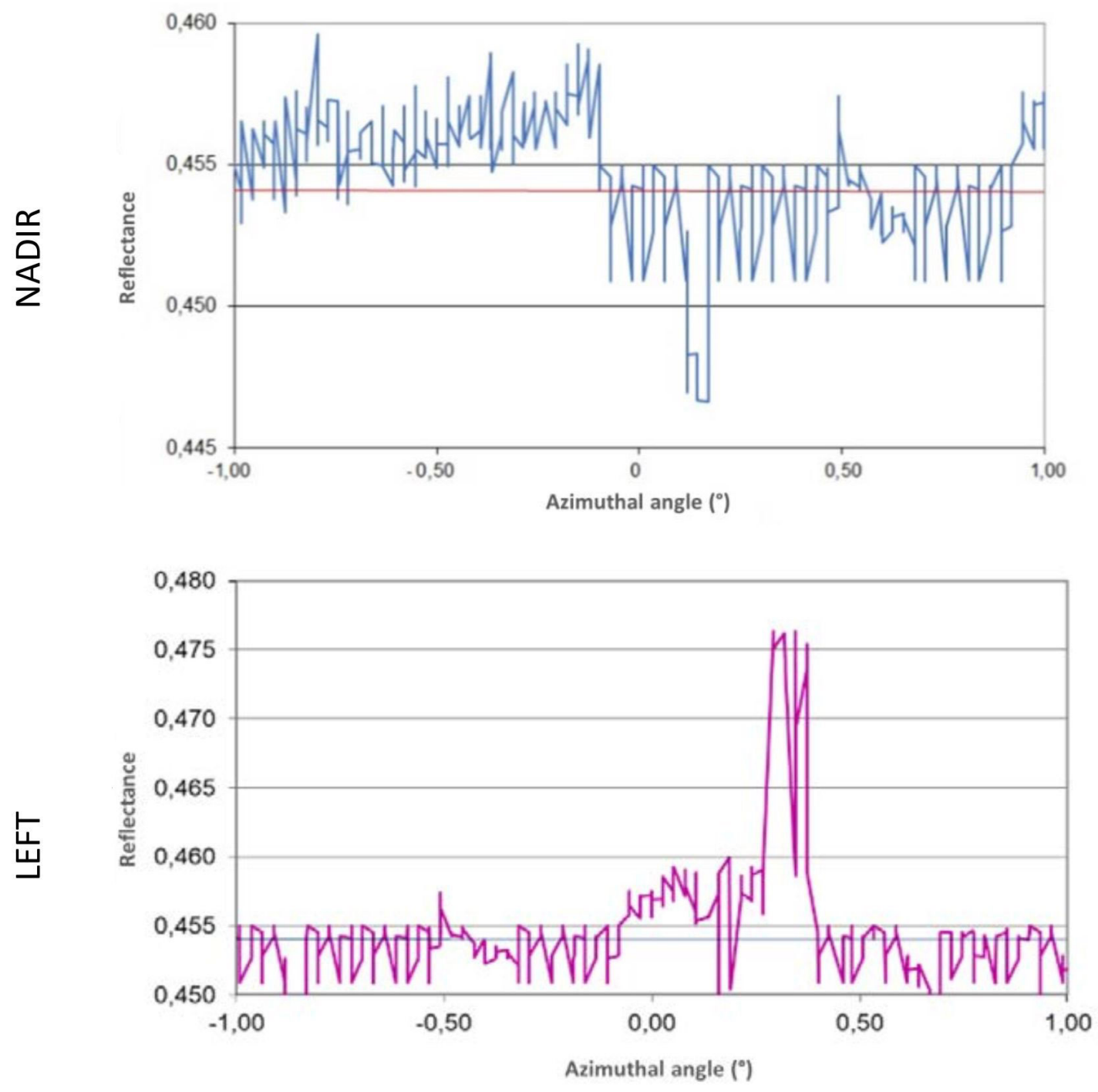

FigurE 16. Tetrafluoroetene reflectance value at different azimuth for Nadir and Left position. 

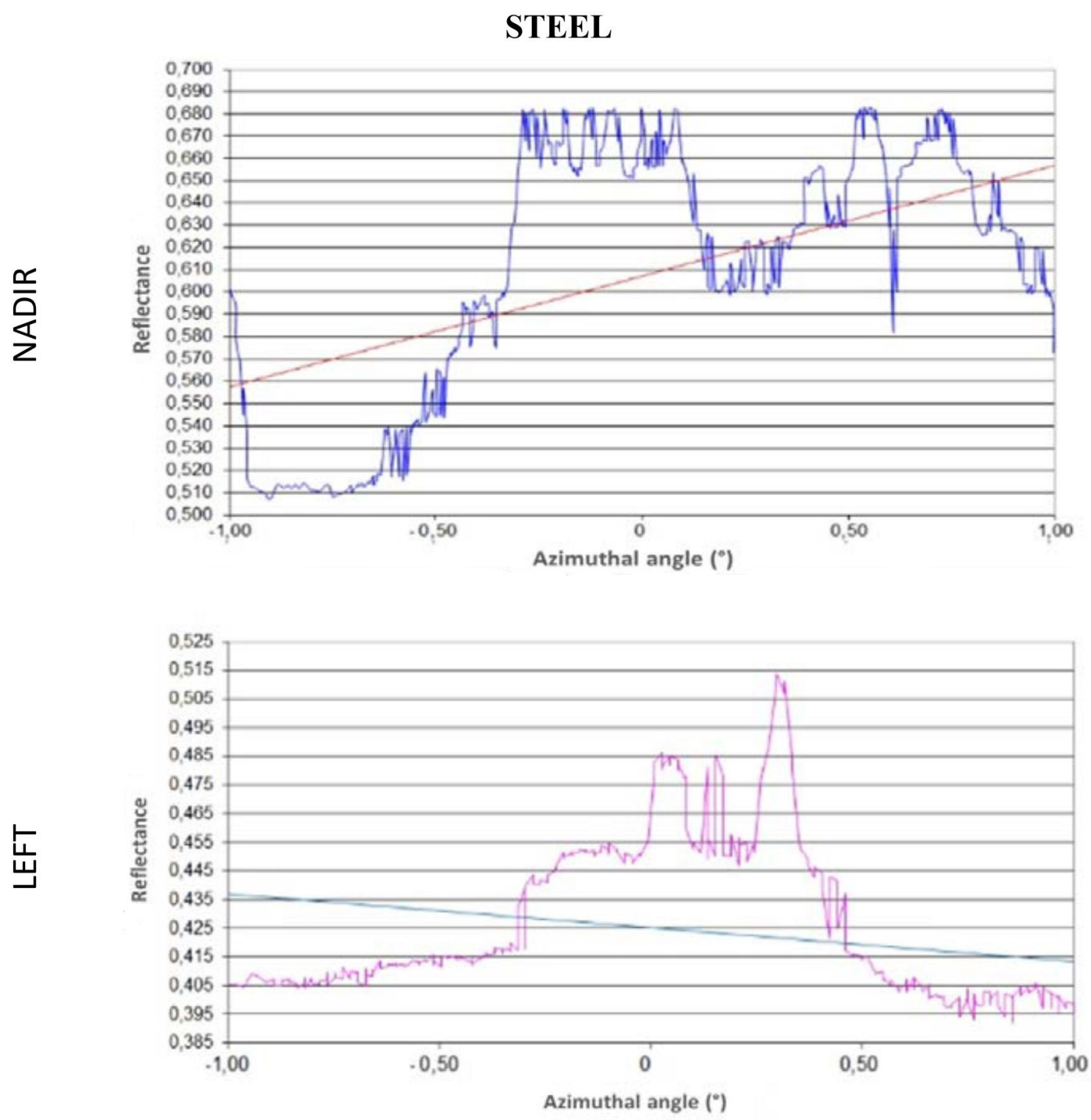

FiguRE 17. Steel reflectance value at different azimuth for Nadir and Left position. 

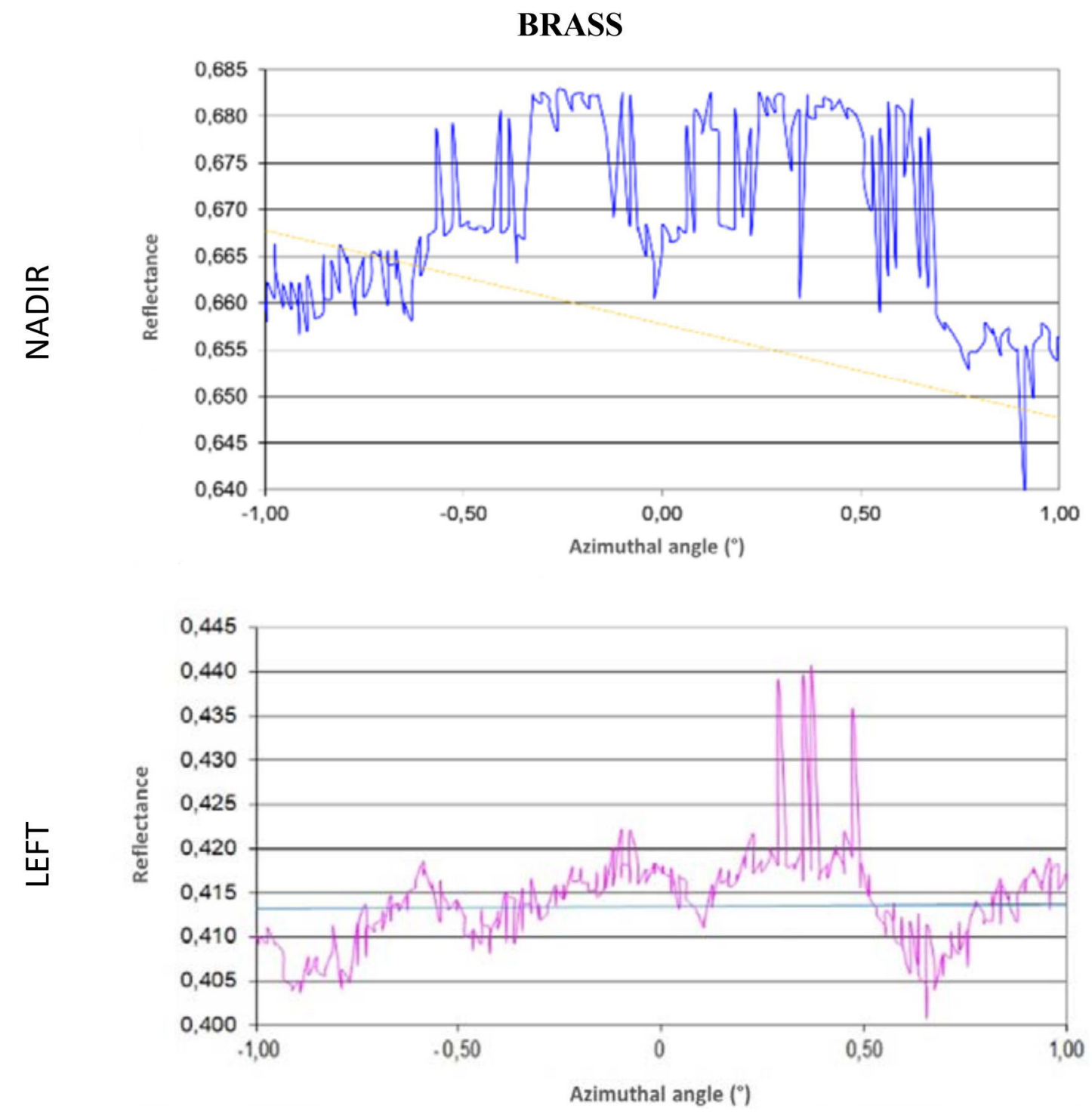

Figure 18. Brass reflectance value at different azimuth for Nadir and Left position. 


\section{HDPE}
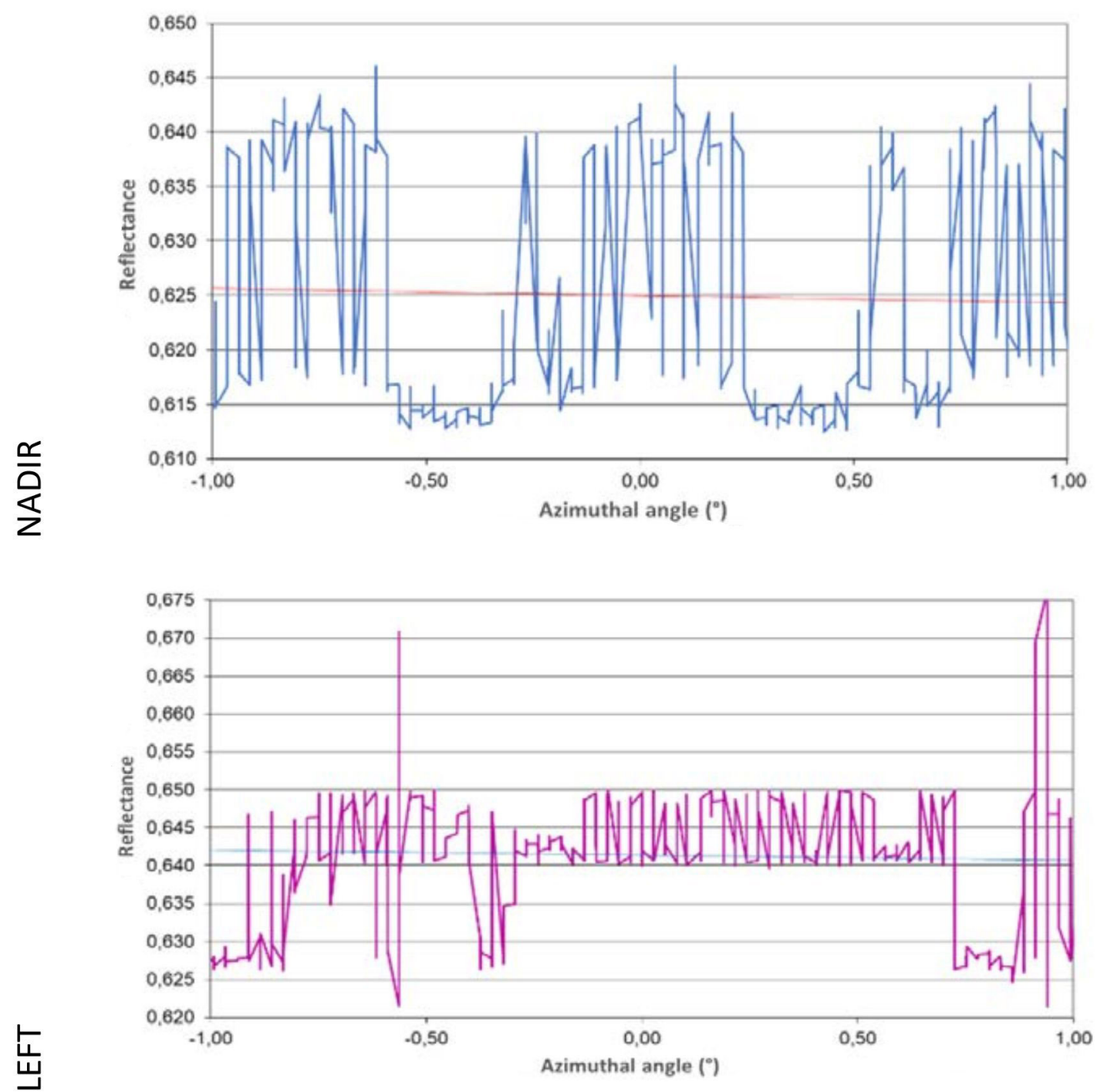

FIGURE 19. HDPE reflectance value at different azimuth for Nadir and Left position. 

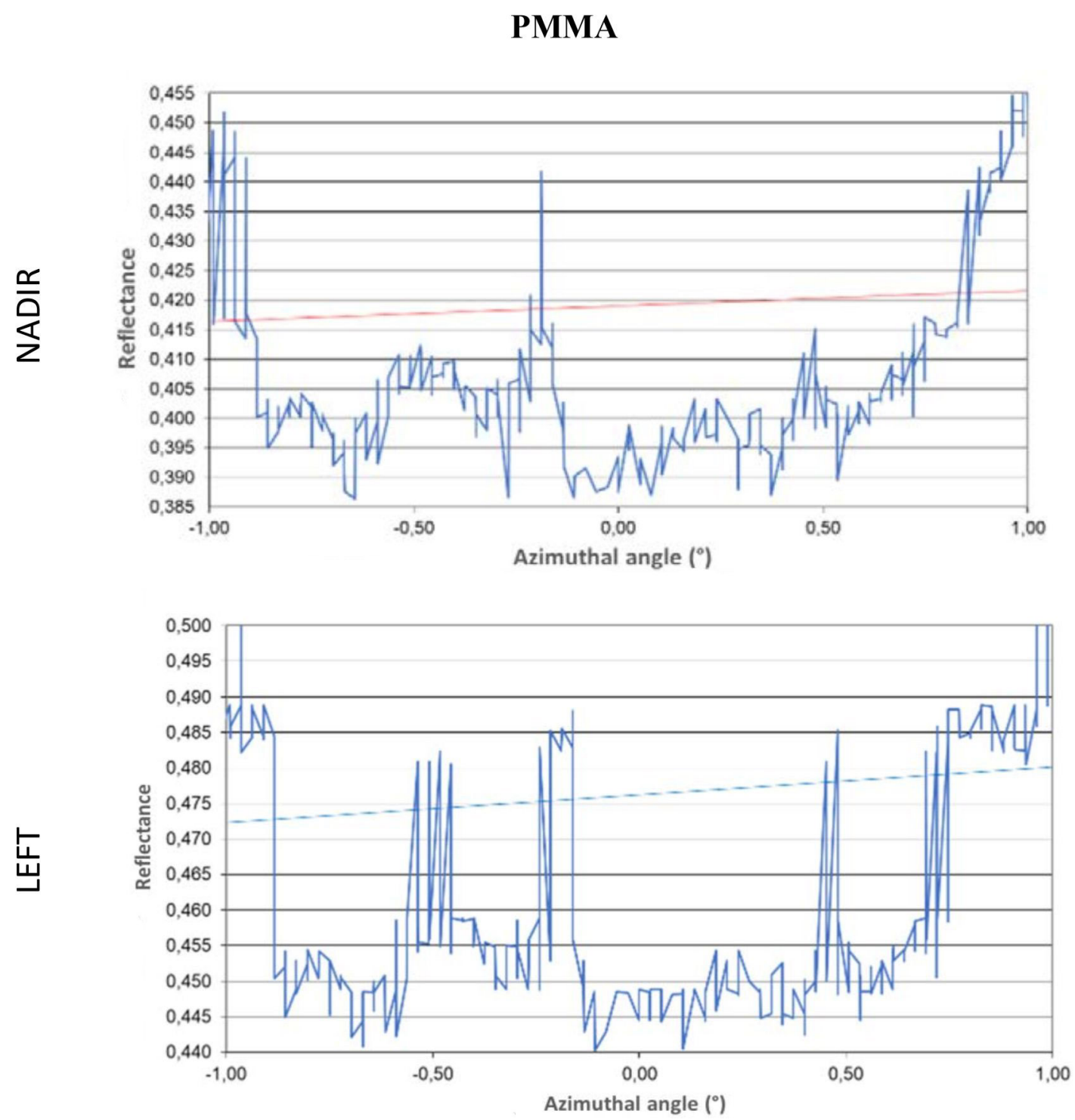

Figure 20. PMMA reflectance value at different azimuth for Nadir and Left position. 
A.3. Appendix 3: Reflectance value obtained with different TLS instruments for MATERIALS

菅
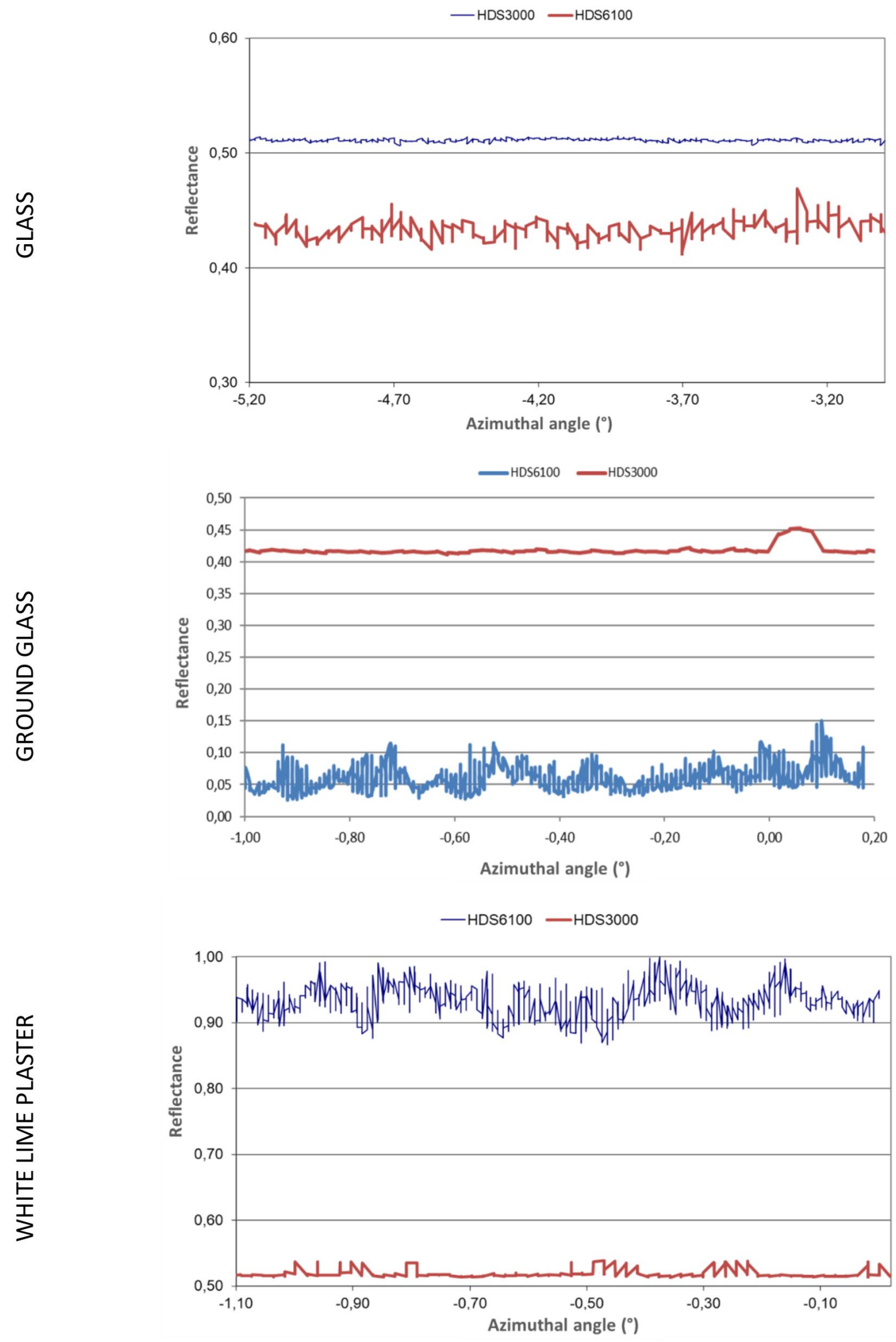

Figure 21. Reflectance values in Nadir position with HDS3000 and HDS6100. 

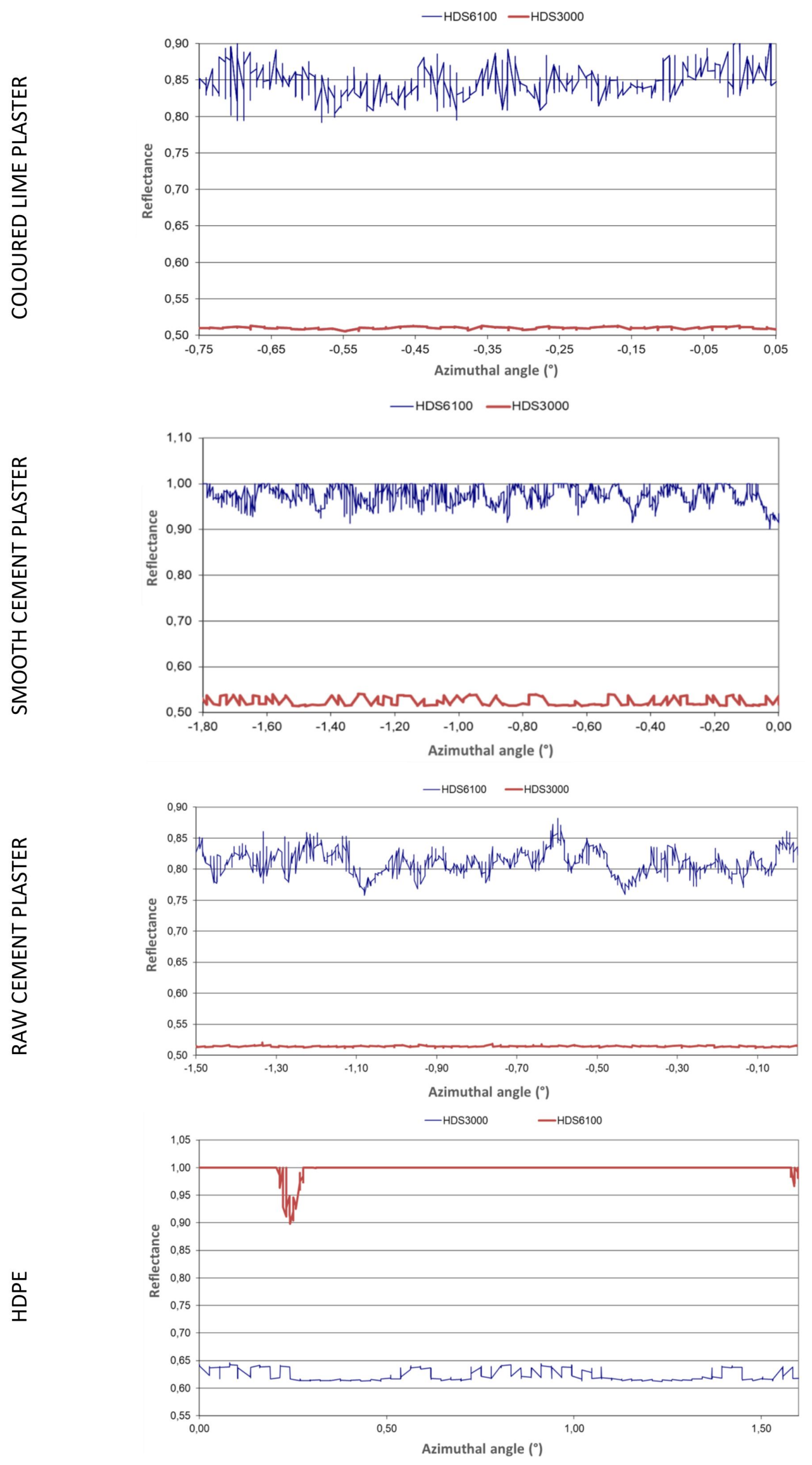

FiguRE 22. Reflectance values in Nadir position with HDS3000 and HDS6100. 